\title{
Principles of Allergen Immunotherapy and Its Clinical Application in China: Contrasts and Comparisons with the USA
}

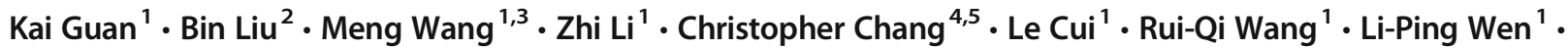 \\ Patrick S. C. Leung ${ }^{4}$ (D) Ji-Fu Wei ${ }^{6} \cdot$ Jin-Lyu Sun $^{1}$
}

Published online: 26 June 2019

(C) Springer Science+Business Media, LLC, part of Springer Nature 2019

\begin{abstract}
Allergen immunotherapy (AIT) for allergic rhinitis (AR), asthma, and other allergic diseases has developed quickly. House dust mite (HDM), Artemisia (wormwood), Humulus japonicus (Japanese hop), Alternaria alternata, and Cladosporium herbarum are the five most common inhalant allergens in China. AIT has been performed in China for over 60 years. With the support of the Chinese Medical Association (CMA) and the Chinese Medical Doctors Association (CMDA), the Chinese College of Allergy and Asthma (CCAA) was established in 2016 as a specialized branch of CDMA and is the main certification authority for AIT. Chinese allergists and scientists have made tremendous progress in the development of AIT. There have been many publications by Chinese allergists and scientists worldwide encompassing original research studies, systematic reviews, case studies, and clinical trials. Currently, conventional subcutaneous immunotherapy (SCIT) is the preferred AIT in China, but sublingual immunotherapy (SLIT) is beginning to gain recognition. An increasing number of clinical trials have been conducted to investigate the clinical efficacy and side effects of SLIT and SCIT. In China, HDM is the only commercial standardized allergen extracts in clinical use, whereas the others are crude allergen extracts. Besides standardized allergen extracts, other forms of hypoallergenic extracts are still being investigated and developed in China. Immunotherapy in China is similar to that in the USA in which allergen extracts can be mixed for SCIT. However, allergen extracts cannot be mixed for SCIT in Europe.
\end{abstract}

Keywords Allergen-specific immunotherapy $\cdot$ Sublingual immunotherapy $\cdot$ Subcutaneous immunotherapy $\cdot$ Allergic rhinitis

\section{Abbreviations}

AEs Adverse events

AIT Allergen immunotherapy

AR Allergic rhinitis

AASS Average Adjusted Symptom Score

CFDA China Food and Drug Administration

$\begin{array}{ll}\text { CCAA } & \text { Chinese College of Allergy and Asthma } \\ \text { CMA } & \text { Chinese Medical Association } \\ \text { CMDA } & \text { Chinese Medical Doctors Association } \\ \text { CS } & \text { Chitosan } \\ \text { CPE } & \text { Complete peanut extract } \\ \text { CVA } & \text { Cough variant asthma }\end{array}$

Kai Guan, Bin Liu and Meng Wang contributed equally to this work

Patrick S. C. Leung

psleung@ucdavis.edu

$\triangle$ Ji-Fu Wei

weijifu@hotmail.com

Jin-Lyu Sun
sunjinlv@pumch.cn

1 Department of Allergy, Peking Union Medical College Hospital, Chinese Academy of Medical Sciences, Beijing 100730, People's Republic of China

2 Department of Immunology and Rheumatology, The Affiliated Hospital of Qingdao University, Qingdao, Shandong 266001, People's Republic of China
3 Department of Ophthalmology, Peking Union Medical College Hospital, Chinese Academy of Medical Sciences, Beijing 100730, People's Republic of China

4 Division of Rheumatology, Allergy and Clinical Immunology, University of California at Davis, 451 E Health Sciences Drive, Suite 6510, Davis, CA 95616, USA

5 Pediatric Immunology and Allergy, Joe DiMaggio Children's Hospital, Memorial Health Systems, Hollywood, FL 33021, USA

6 Research Division of Clinical Pharmacology, the First Affiliated Hospital of Nanjing Medical University, Nanjing, Jiangsu 210029, People's Republic of China 


$\begin{array}{ll}\text { DC } & \text { Dendritic cells } \\ \text { DCN } & \begin{array}{l}\text { Dermatophagoides chitosan nanoparticle } \\ \text { Der f }\end{array} \\ \text { EAACI } & \begin{array}{l}\text { Dermatophagoides farinae } \\ \text { European Academy of Allergology } \\ \text { and Clinical Immunology }\end{array} \\ \text { HMSNs } & \text { Hollow mesoporous silica nanoparticles } \\ \text { HDM } & \text { House dust mite } \\ \text { LAB } & \text { Lactic acid bacteria } \\ \text { MSNs } & \text { Mesoporus silica nanoparticles } \\ \text { OVA } & \text { Ovalbumin } \\ \text { PUMCH } & \text { Peking Union Medical College Hospital } \\ \text { RQLQ } & \text { Rhinoconjunctivitis Quality of Life } \\ & \text { Questionnaire } \\ \text { RIT } & \text { Rush immunotherapy } \\ \text { SPT } & \text { Skin prick testing } \\ \text { SCIT } & \text { Subcutaneous immunotherapy } \\ \text { SLIT } & \text { Sublingual immunotherapy } \\ \text { TLR7 } & \text { Toll-like receptor 7 } \\ \text { TNSS } & \text { Total Nasal Symptom Scores } \\ \text { VAS } & \text { Visual analog scores }\end{array}$

\section{Introduction}

Over the last four decades, the prevalence of asthma, allergic rhinitis (AR), and atopic dermatitis has been increasing worldwide, affecting patients' quality of life and generating a significant economic burden [1]. This is also the case in many regions and cities in China. The prevalence of adult AR in the 18 major cities of China was $17.6 \%$ in 2011 [2].

The editorial board of the Chinese Journal of Otorhinolaryngology was established in 1990 and has since introduced five updated Chinese guidelines for AR. The most recent Chinese guidelines for AR was published in English literature in Allergy, Asthma \& Immunology Research in 2018 [3-5].

The current recommended treatment paradigm for AR mainly includes (a) allergen and irritant avoidance, (b) pharmaceuticals, (c) doctor-patient interaction and education, and (d) specific allergen immunotherapy (AIT) [1]. AIT is the only current medical intervention that can potentially affect the natural course of allergic diseases [6, 7]. In 1911, Leonard Noon and John Freeman first introduced AIT in their article on 'Prophylactic inoculation against hay fever' [8]. William Frankland et al. published the first randomized controlled trial in AIT on subcutaneous grass pollen immunotherapy [8]. In 2006, the European Academy of Allergology and Clinical Immunology (EAACI) noted that AIT was a cause-targeted treatment that changed the development of the disease process [6]. Through the years, AIT has been shown to be an effective therapeutic approach in patients with AR, allergic conjunctivitis, allergic asthma, and hymenoptera venom allergy [1].
In China, treatment of allergies with allergen immunotherapy began about 60 years ago. Since then, and paralleling the increasing number of patients with allergic disorders in China, AIT has become widely used and investigated. Ninety-six percent of Chinese ENT specialists believe that AIT is the preferred treatment for AR and allergic asthma [9]. Chinese guidelines for the use of AIT [10] as well as an expert consensus document on subcutaneous immunotherapy (SCIT) have been published [11]. Similar to international guidelines, Chinese doctors recommend earlier initiation of AIT for AR patients if appropriate resources are available, and are not limited to patients who fail drug treatment only $[10,11]$. Many published studies of AIT in China are in the Chinese literature and written in Chinese, rendering them inaccessible or incomprehensible to international readers.

\section{Geoepidemiology of Inhalant Allergens in China and Other Countries}

AIT is an effective treatment for allergenic disorders due to inhalant allergens. Biological components from pollens, fungus, dust mites, insects, and animal hair are the most common environmental inhalant allergens. A multicenter study involving 14 countries in Europe reported that grass pollen, house dust mite, birch pollen, cat dander, olive pollen, mugwort, German cockroach, and the mold Alternaria are the most prevalent allergens in a majority of the subjects in these countries [12]. However, there is still great variation regarding which allergens are the most prevalent in each country.

Allergic rhinitis is a global health care issue that affects $23-$ $30 \%$ of the European population $[13,14]$ and $12-30 \%$ of the US populations [15]. Data from a nationwide survey on the prevalence of allergic rhinitis in children of 6-13 years old in eight metropolitan cities (Shanghai, Guangzhou, Xian, Wuhan, Harbin, Chengdu, Hohhot, and Urumiqi) in China showed that the mean prevalence of childhood allergic rhinitis was $9.8 \%$, ranging from $3.9 \%$ in Xian to $16.8 \%$ in Guangzhou [16]. Another study reported that the prevalence of allergic asthma in children $0-14$ years old was $14.4,20.42$, and $7.83 \%$ in Beijing, Chongqing, and Guangzhou, respectively [17].

The prevalence of allergic rhinitis in Chinese adult populations is also highly variable. A nationwide study in 11 major cities across China reported that the prevalence of allergic rhinitis was $8.7 \%$ in Beijing, $11.2 \%$ in Changchum, $16.1 \%$ in Changsa, $14.1 \%$ in Guangzhou, $8.9 \%$ in Hangzhou, $13.3 \%$ in Nanjing, $13.6 \%$ in Shanghai, $15.7 \%$ in Shenyang, $19.3 \%$ in Wuhan, $9.1 \%$ in Xian, and $24.1 \%$ in Urumqi [18]. The spectra of inhaled allergens are similar to western countries, with pollen, dust mites, mugwort, fungus, animal dander, and cockroach being the most common ones [19]. Interestingly, sensitization to silk is identified as the strongest 
predictor of rhinitis in Anqing population [20], while Chenopodium and Humulus lupulus are identified as an inhalant allergen in Changji. The prevalence of pollen-induced AR is extremely high in the grasslands of northern China due to high seasonal pollen exposure, largely influenced by local environmental and climate conditions. A recent study using interviewer-administered questionnaire and SPT on $6043 \mathrm{sub-}$ jects from random sampling found that 32.4 and $18.5 \%$ of the subjects had epidemiologic AR and pollen-induced AR, respectively, in the inner Mongolia grasslands [21]. A retrospective study on the prevalence and trend of sensitization to aeroallegens in patients with allergic rhinitis in Guangzhou showed that while house dust mite is the most common allergen, there is an increasing trend of pet allergen sensitization from 2005 to 2014 [22].

Japanese cedar pollen is the most common allergen in Japan [23]. A study on 408 healthy infants in Japan found that $44 / 408$ (10.7\%) had IgE antibodies to one or more aeroallergens including house dust mites, cat fur, and Japanese cedar pollen. In addition, 8/408 (2.0\%) had nasal eosinophils [24]. In another study, the mean age of onset of asthma in Japan was $2.3 \pm 1.9$ years [25]. A more recent study on 8815 children between 6 and 9 years old demonstrated that indicated 39\% are sensitized to Japanese cedar pollen [26].

A 2017 study assessed the safety of allergen immunotherapy in the USA. Based on a national survey of allergists, there was one fatal reaction after every 2.5 million injection visits between the years 1990 and 2001, based on a national survey of allergists [27]. This equated to 3.4 fatal reactions per year. The study also found that the rate of systemic reactions with SCIT was about $0.1-0.2 \%$ for conventional buildup schedules. This rate increased with cluster IT and there were 11 cases of nonfatal anaphylaxis resulting from $1 \times 10^{9}$ sublingual immunotherapy (SLIT) doses.

In the USA, there are currently four FDA-approved sublingual therapies, which are for timothy grass, a grass mix, dust mite, and ragweed. A recent survey was conducted on the perception of sublingual immunotherapy in allergists in the USA [28]. This study revealed that there has been a marked increase in the use of sublingual immunotherapy over the past 5 years. In fact, 297 of 268 respondents (73.5\%) from the USA have used sublingual immunotherapy, which is a significant increase over $5.9 \%$ in 2007 and $11.4 \%$ in 2011 . The main limitation in sublingual therapy was that each approved therapy only treats a single allergen.

When prescribing AIT, health professionals should carefully consider the relevance of the allergens to individual patients and use allergen extracts with proven safety and efficacy. Since in many countries AIT is prescribed by primary care providers, updated training on the most current understanding of AIT and evidence-based primary care allergy guidelines are greatly needed for optimal treatment for allergy patients [29].

\section{Distribution of Common Allergens in China}

As in the rest of the world, house dust mite (HDM) is the most common indoor allergen in China (Figs. 1 and 2) [30]. In 2012, we summarized two hundred thousand allergenspecific immunoglobulin E (sIgE) results at Peking Union Medical College Hospital and found that HDM, Artemisia (wormwood), Humulus japonicus (Japanese Hop), Alternaria alternata, and Cladosporium herbarum were the most common inhalant allergens [31].

\section{House Dust Mite}

In China, the most important allergenic mites found in homes are Dermatophagoides farinae and Dermatophagoides pteronyssinus and the storage mite Blomia tropicalis [32]. The seasonal distribution of each mite species may be variable. Our study analyzed 1798 separate mite and insect specimens in 345 dust samples in Beijing and reported that $D$. farinae was the predominant species, followed by D. pteronyssinus and D. siboney [33]. The seasonal density distribution of HDM showed the highest mite concentration in September through October, followed by May through July, and lowest in March and November [34]. However, in Wuhan, located in central China, the overall mite detection rates were 67.4\% from April to July, 22.4\% from August to October, and $10.2 \%$ from November to March [35]. In Xishuangbanna, a tropical rainforest in southwest China, the mite family Pyroglyphidae, including D. farinae, D. pteronyssinus, and $D$. siboney, are the most common species year round because of the relatively stable yearly temperature in the tropical rainforest climate [36].

\section{Artemisia and Japanese Hop}

The weed pollens from Artemisia (Fig. 3) and Humulus japonicus (H. japonicus) (Fig. 4) are two of the most important fall seasonal allergens in China. Common species of Artemisia found in China include Artemisia annua, Artemisia capillaries, and Artemisia sieversiana. Artemisia are biennial herbs and their pollen grains are either spherical or oblate spherical, ranging from 20 to $30 \mu \mathrm{m}$ in diameter. Depending on the weather and region, they usually bloom from July to September with a 2-month flowering period. Artemisia species are present throughout the country, growing on wasteland, mountain slopes, and forest edges. Sensitization to Artemisia pollen increases with age, affecting $5.06 \%$ of children under and $15.45 \%$ above 5 years of age [37]. Two studies in Hubei Province showed that 10.5\% (189/1800) of AR patients in Jingmen City [38] and 5.5\% (12/216) asthmatic children in Wuhan City [39] are sensitized to Artemisia.

$H$. japonicus is an annotinous or perennial twining flowery herb characterized by creeping stems with spiny hair and 


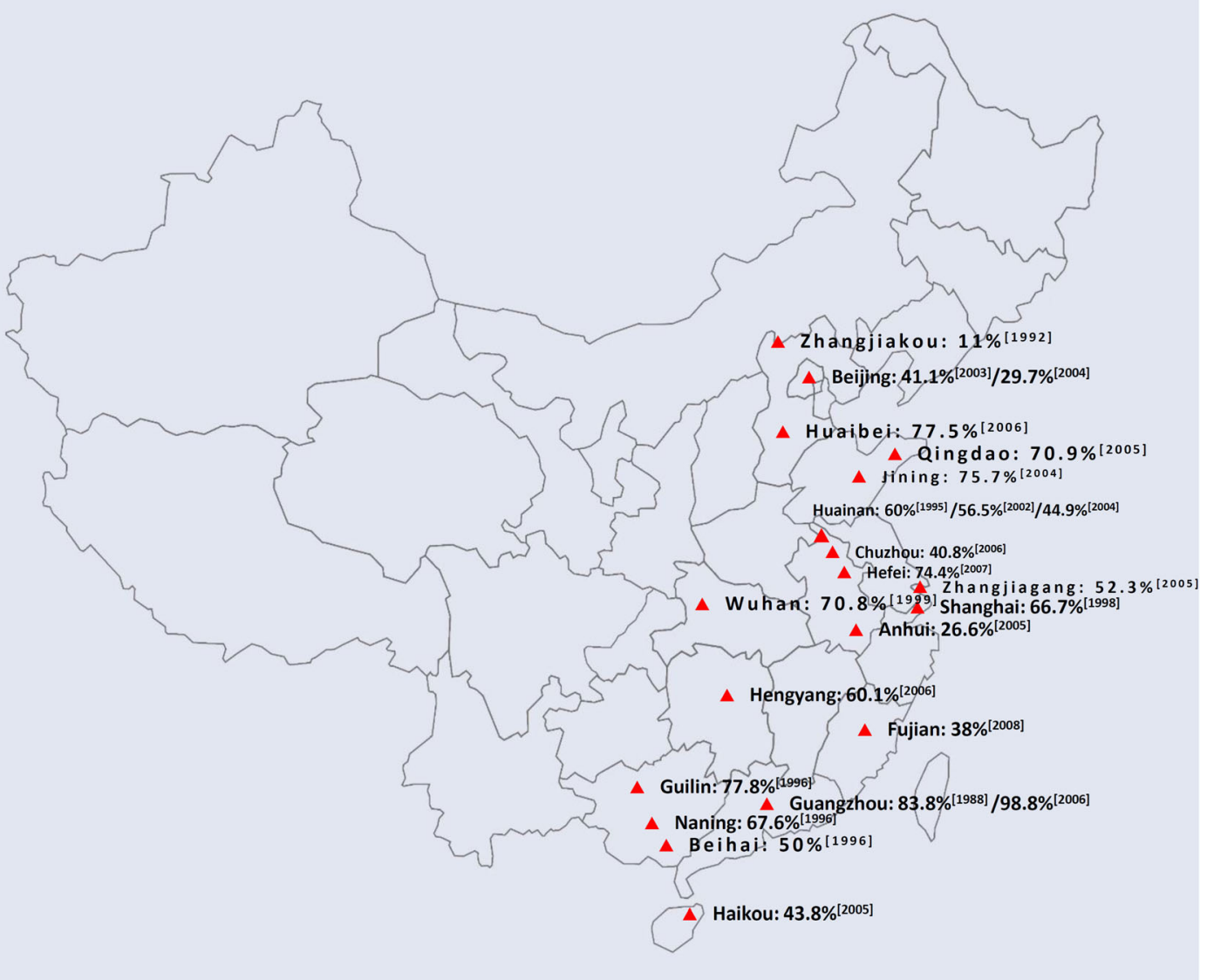

Fig. 1 Distribution of house dust mites in different regions in China

spherically shaped pollen grains of about $30 \mu \mathrm{m}$. It flowers from July through September. H. japonicus is found throughout nearly the entire country, except for Qinghai and Xinjiang provinces. It grows by gullies and the roadsides. It can also be found in other Asian countries, including Japan and Korea [40].

H. japonicus pollen is more commonly detected in northern China than southern China (Fig. 5) [37-39, 41-68]. Sensitization to $H$. japonicus is as high as $21.8 \%$ in the Shandong coastal area [46].

\section{Alternaria alternata and Cladosporium herbarum}

Molds are also important perennial allergens in China. Most in vivo and in vitro testing in China is done with a mixed mold extract. However, it is known that A. alternata and C. herbarum are widely distributed in China. In Guangdong Province, A. alternata sensitivity was present in $14.9 \%$ (59/ 397 ) of children with asthma [56] and in 44.9\% (730/1625) of patients with allergic rhinitis [58], whereas $C$. herbarum was positive in $47.4 \%(771 / 1625)$ of patients with allergic rhinitis [58]. C. herbarum was positive in 3.6\% (16/450) of children with asthma in Hainan, the southernmost province of China [60].

\section{History of Allergen Immunotherapy in China}

The first allergy department in China was established at the Peking Union Medical College Hospital (PUMCH) in 1956. The first generation of Chinese clinical allergists prepared allergen extracts from pollen, dust mites, fungi, animal dander, and insects for skin prick testing (SPT) and AIT [69]. During the first 40 years, only crude extracts were available for AIT, and SCIT was the only administration route. SLIT for D. farinae was later introduced in China in 2006. Intralymphatic immunotherapy has also been reported [70].

In China, almost half of the patients with autumn pollen AR develop seasonal allergic asthma within 9 years [71-73]. Currently, only three standardized allergen extracts of HDM have been approved by the China Food and Drug Administration (CFDA) for AIT use in China. NovoHelisen-Depot (Allergopharma Joachim Ganzer KG, Germany) (CFDA approved in 1999) was the first of these to be approved. However, Alutard-SQ (ALK-Abelló, 


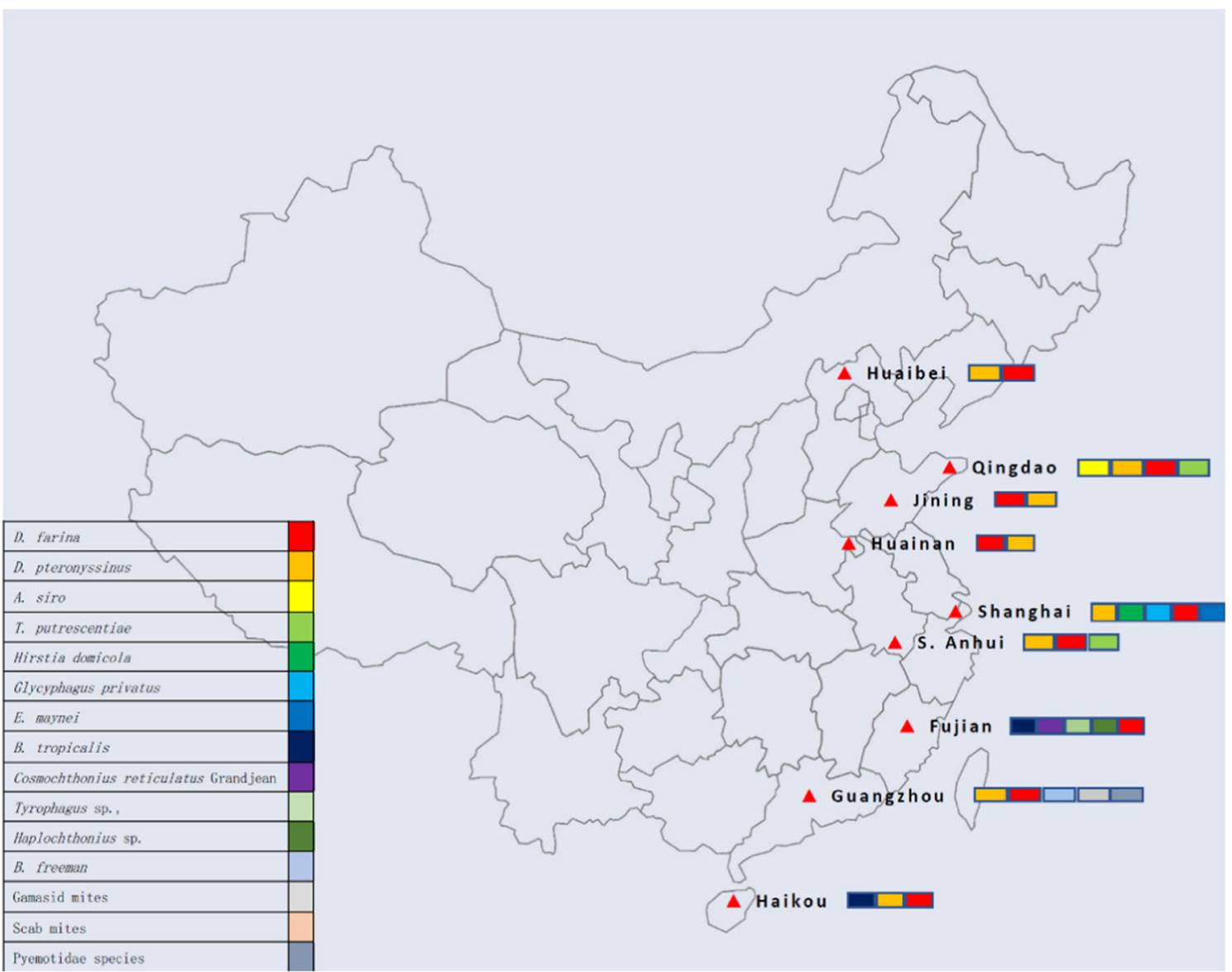

Fig. 2 Various kinds of house dust mites in China

Denmark) (CFDA approved in 2004) is now much more widely used for SCIT in China. Chanllergen-Df Drops (Wolwo Pharma, China) (CFDA approved in 2006) is the only SLIT product available in China. There are also many crude allergen extracts used in China. Compared to Western countries, AIT in China began much later but is becoming more available in many centers throughout China.

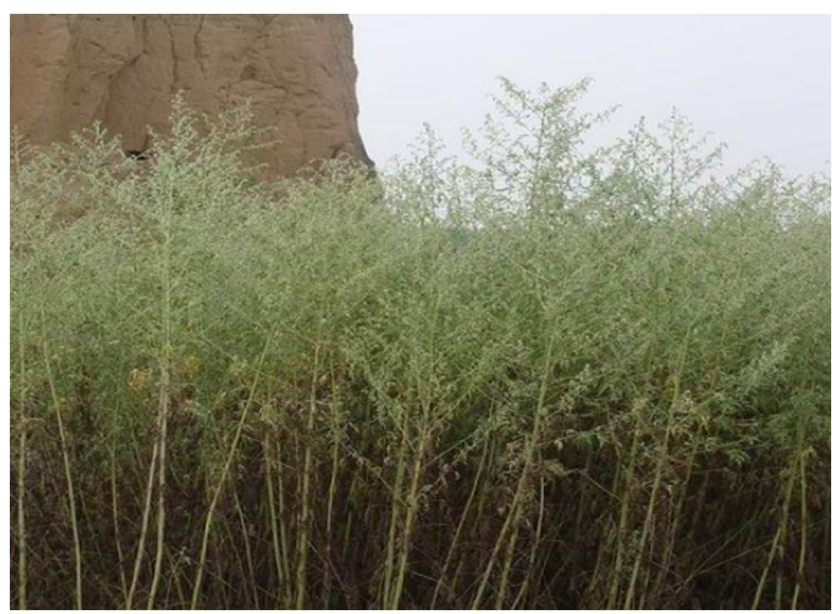

Fig. 3 Artemisia sieversiana

\section{AlT in China}

\section{SCIT}

\section{SCIT with HDM Allergen Extracts}

There have been several studies on the long-term therapeutic effects of SCIT with standardized HDM in AR or asthma patients in China [74-90], including double-blind placebo-

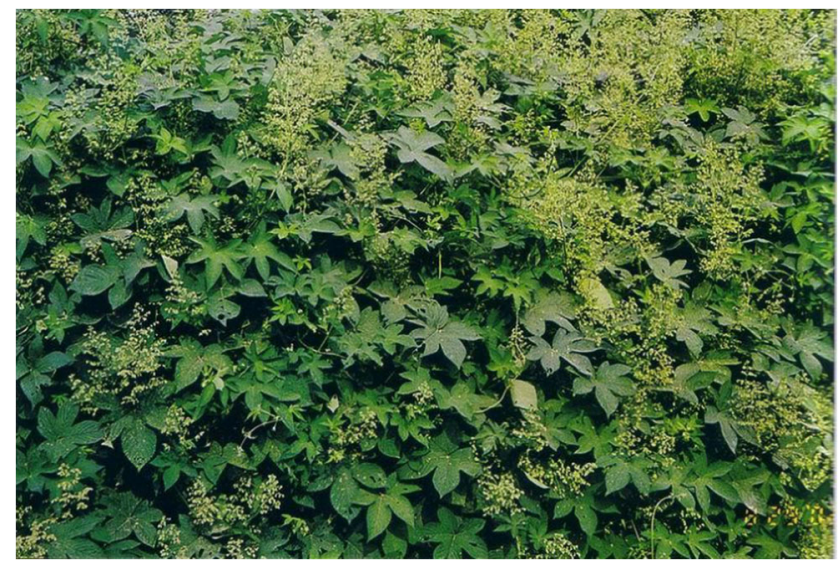

Fig. 4 Humulus japonicus 
a

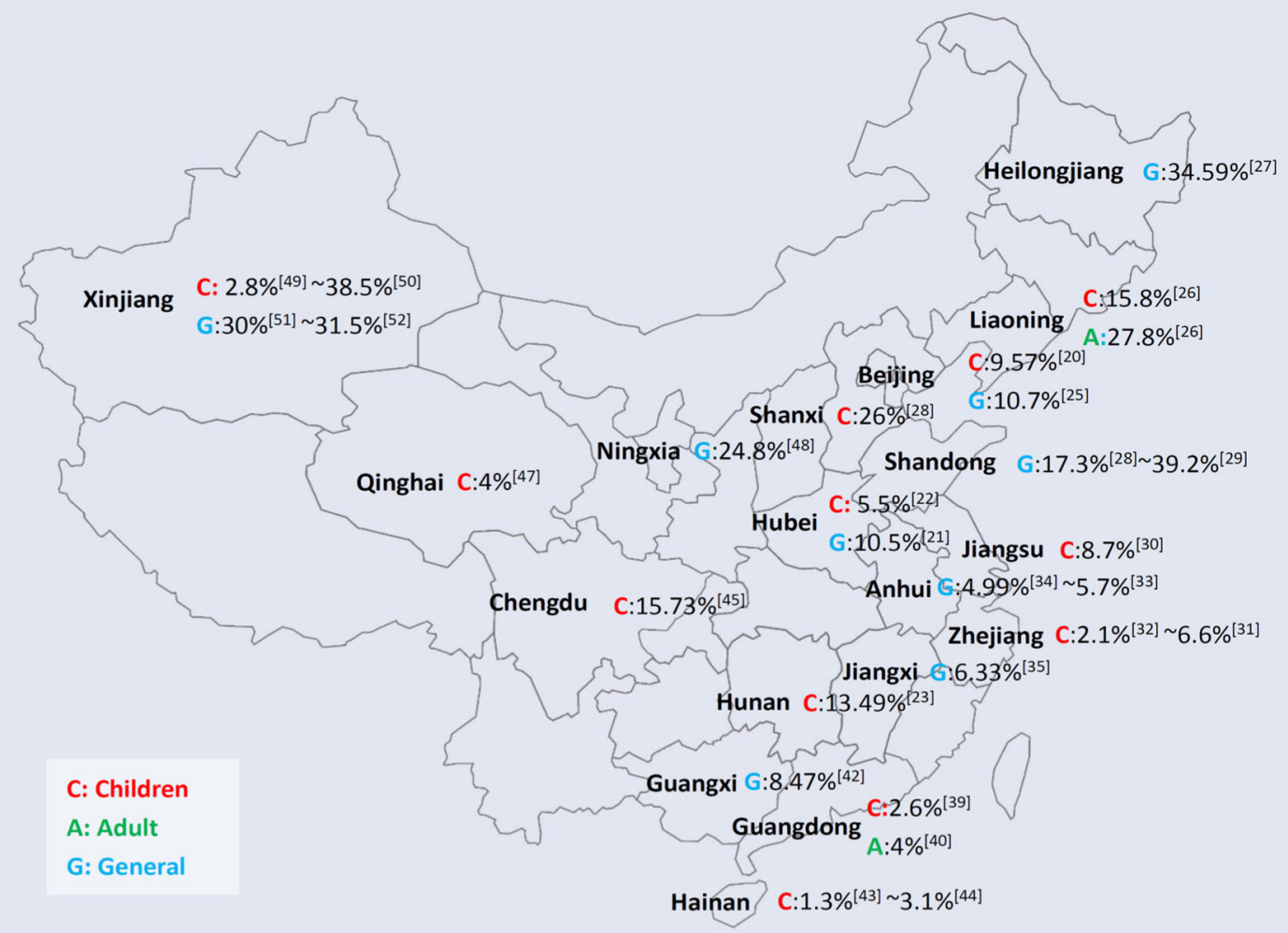

b

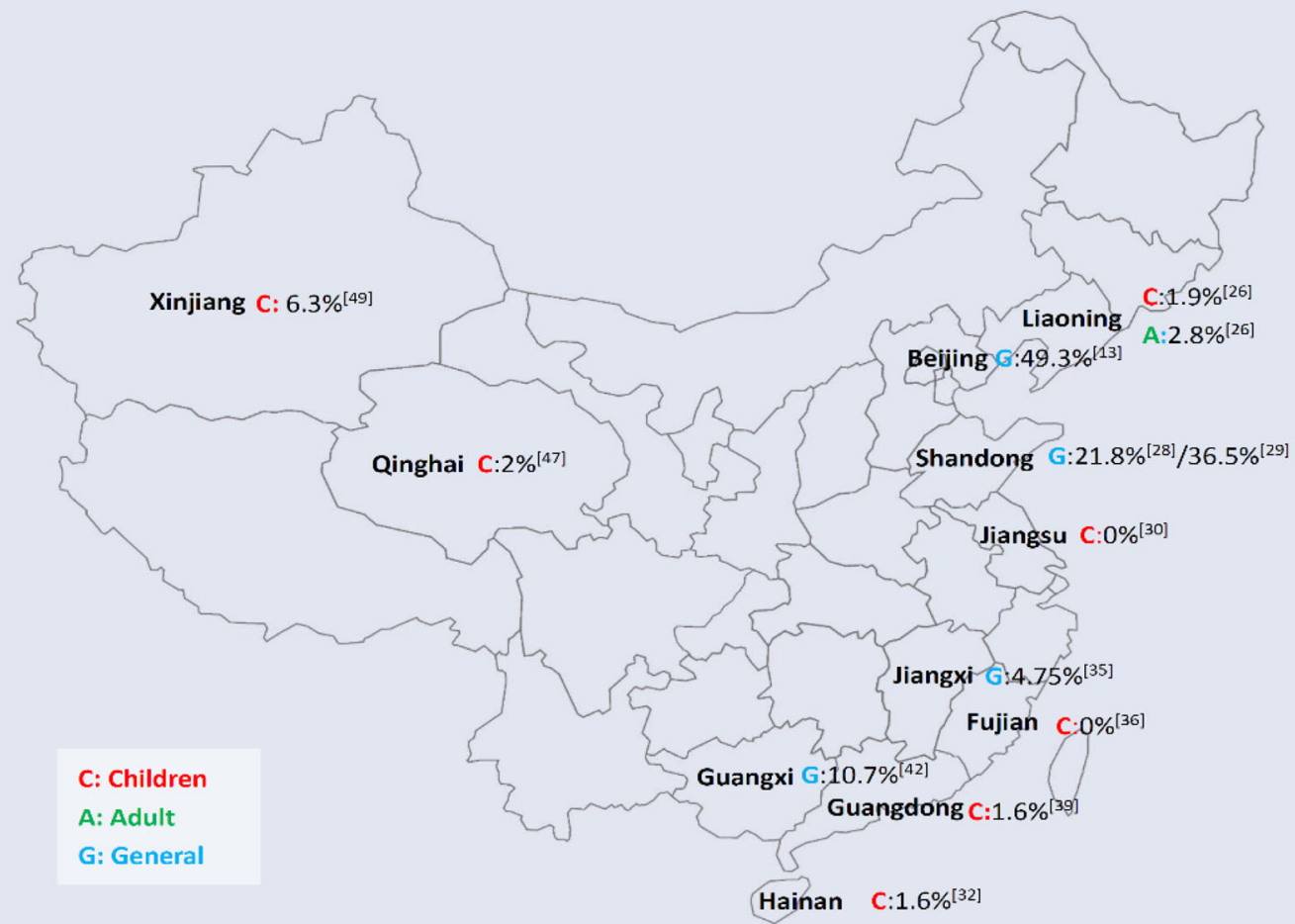

Fig. 5 Sensitization to Artemisia (a) and Humulus japonicus (b) in China 
controlled studies [84]. Data from these studies indicate that SCIT is an effective and promising treatment of AR in Chinese patients. The following endpoints have been studied: (1) reduced or completely controlled allergy symptoms and improvement in quality of life, (2) reduced symptomatic treatment medication, (3) remodeling of the immune system, (4) preventing AR from developing into asthma, and (5) preventing new allergies.

A double-blind, placebo-controlled study involving 132 asthmatic subjects from three different regions of Mainland China was by far the largest randomized controlled trial in China to investigate the effect of SCIT with Alutard-SQ [84]. The symptom scores began to diverge at week 29 with the immunotherapy group showing a significantly lower score until week 48 . In actively treated subjects, skin test response decreased but Der $p$ sIgE remained unchanged. Another study used Total Nasal Symptoms Scores (TNSS) and Rhinoconjunctivitis Quality of Life Questionnaire (RQLQ) to assess nasal symptoms and quality of life in 47 AR patients and reported that the efficacy started and kept improving 3 months after treatment and remained relatively stable after 1 year [75].

A study on AR patients in Guangzhou City showed that there was no significant difference in the efficacy of SLIT between dust mite monosensitized and polysensitized patients [91]. Similarly, another study in Chongqing showed that asthma children with multi-allergen sensitization could be desensitized by a single HDM-SCIT, which could also help prevent the onset of new sensitization [85]. It should be noted that although standardized HDM vaccine can rapidly improve large airway function following the commencement of treatment, its effect on small airways can be delayed [86]. Moreover, patients with severe asthma tend to be responders rather than nonresponders [87, 89]. AIT was more effective in children compared to adults [76]. In HDM-induced atopic dermatitis patients, HDM-SCIT relieved clinical symptoms and altered levels of IL-10, TGF-beta1, s-IgG4, and IFN- $\gamma$ [92].

\section{SCIT with Other Allergen Extracts}

Many nonstandardized crude extracts have been used in China for a long time. The advantages of nonstandardized allergen extracts include a wider variety of allergen extract, lower cost, and the ability to offer mixed allergen extracts. In 1987, Leng et al. [93] studied AIT with Artemisia pollen allergen extract in China. This was the earliest international report of AIT in China. Humulus pollen extract has been found to be effective and safe for use in AR with/without asthma [94]. Similarly, significant improvement in symptom scores, lung function, medication scores, eosinophil count, and SPT index has been reported after nonstandardized AIT with ragweed and/or mugwort extracts [95].

\section{SLIT}

\section{SLIT with HDM Allergen Extracts}

The long-term therapeutic effects of SLIT for HDM in AR or asthma were examined in various studies, [95-119] including five that were double-blind placebo controlled [96, 102, 103, 115, 120]. One meta-analysis evaluating 25 studies reported that SLIT provided significant relief in symptom and reduced the need for medications in persistent AR [121].

A double-blind placebo-controlled randomized clinical trial of 484 asthmatic adults showed that sublingual HDM allergen immunotherapy was well tolerated in adult asthmatics and effectively controlled disease in patients with moderate (but not mild) persistent asthma [96]. Another multicentered, randomized, double-blind, placebo-controlled study of SLIT on 120 HDM-induced AR patients showed that the total symptom and visual analog scores (VAS) in the SLIT group decreased significantly after week 14, and individual AR symptoms were significantly improved after week 22 [103]. Similarly, Yue et al. performed SLIT with Der $f$ drops on patients with $\operatorname{Der} f$ allergic asthma and rhinitis and further confirmed the safety and effectiveness of SLIT [104]. The onset of the action can be observed as early as 3 months after initiation of treatment [122].

The efficacy and safety of SLIT in children, especially very young children, was also demonstrated [105, 123]. For patients with cough variant asthma (CVA) [106] and atopic dermatitis [116], similar therapeutic effectiveness of SLIT was noted. Longer duration of SLIT treatment over a 3-year course is more efficacious than a 1- or 2-year course [124].

\section{SCIT Vs SLIT}

SCIT and SLIT are both effective treatments for allergic diseases [125-129]. In general, SLIT appears to be associated with fewer and less severe adverse reactions than SCIT [130], while SCIT usually has higher efficacy and faster onset. After 2 years of AIT with standardized HDM extract for patients with persistent AR, no significant difference was found in the reduction of the total nasal symptoms between the SCIT and SLIT groups. However, there was a significant reduction of VAS score of nasal obstruction in the SCIT group compared with the SLIT group [112]. Similar findings on the effectiveness of SCIT and SLIT were reported in other studies $[113,131,132]$. However, Gui et al. [114] performed AIT in 248 AR patients and observed a significant difference of response rate between the SCIT and SLIT groups (92.19 vs. $49.46 \%)$. 


\section{AIT in Other Asian Countries}

HDM

AIT with HDM is not only used to treat AR and asthma, but also AD. Nahm et al. [133] treated 251 AD patients with HDM extract using SCIT and observed a favorable clinical response rate of $73.6 \%$. Moreover, the response rate of SCIT was significantly higher in patients with severe AD $(90.6 \%)$ than patients with mild to moderate $\mathrm{AD}(63.7 \%)(p<0.001)$. This study showed that early initiation of SCIT might lead to a favorable clinical outcome in patients with severe AD sensitized to HDM.

In 2016, a double-blind trial [134] in Japan assessed the efficacy of SLIT with 300 index of reactivity (IR), 500 IR, or placebo groups in 968 HDM-AR patients. The Average Adjusted Symptom Score (AASS) in the last 8 weeks of treatment was significantly improved in both the 300 IR and the 500 IR groups compared to that in the placebo group $(p<0.001)$. All four nasal symptoms significantly improved in both 300 IR and 500 IR groups. Furthermore, rescue medication use was reduced and the Japanese Rhinoconjunctivitis Quality of Life Questionnaire outcome was also improved in the 300 IR group. Furthermore, a prospective, randomized, controlled, open-labeled, three parallel group trial recruited 48 patients monosensitized to HDM [135] and demonstrated that a significant reduction of total rhinitis and asthma symptom score, total medication score, VAS, and skin reactivity to $\mathrm{HDM}$, as well as serum-specific HDM-IgE, was shown in both SLIT and SCIT groups.

\section{Pollen}

Japanese cedar (Cryptomeria japonica) pollinosis is one of the most common causes of seasonal rhinitis in Japan [136]. In the 1970s, SCIT for cedar pollinosis was performed at university hospitals and medical clinics in Japan [137]. However, in the 1980s, the introduction of second-generation antihistamines and intranasal corticosteroids gradually decreased the use of SCIT. In 2004, a multicenter, double-blind, randomized, placebo-controlled, parallel group study of SLIT demonstrated the safety and beneficial effects of immunotherapy for cedar pollinosis rather than by pharmacotherapy alone [138, 139]. The mean of the daily total symptom scores and the QOL score were significantly lower in the SLIT group than in patients experiencing pollinosis symptom receiving symptomatic treatment [139]. More recent studies also support the effectiveness of AIT in improving nasal and ocular symptoms $[140,141]$. Another study found that the efficacy of SLIT in patients with cedar pollinosis may be induced by apoptosis of $\mathrm{CD}^{+} \mathrm{T}$ cells and basophils [142].

\section{Side Effects of AIT}

AIT can cause local or systemic reactions. Local reactions are more common and expected. Although systemic reactions are part of administering AIT, it is imperative that the clinicians take precautions to minimize the risk of systemic reactions by appropriate patient selection and dose adjustment. SCIT should only be administered by experienced allergists with the proper equipment and medications to treat anaphylaxis. The EAACI, AAAAI, and ACAAI all recommend at least $30 \mathrm{~min}$ of observation after each injection [143]. The incidence of long-term side effects is very low as long as the standard of care is followed. The risk of death from anaphylaxis during AIT is as low as one in 2.5 million injections.

\section{Side Effects of SCIT}

To examine the side effects of SCIT, Lan et al. [144] observed 166 patients who received 3087 injections of AIT (Alutard, ALK-ABELLO, Denmark). Systemic adverse reactions occurred 25 times in eight children which was $0.81 \%$ of the total injections. All the children with systemic adverse reactions manifested a strong positivity to SPT against HDM with rapid recovery after proper treatment (Table 1).

In a retrospective study on patients receiving SCIT with crude pollen allergen extracts over a 20 -year period between December 1993 to September 2013, 70 systemic adverse reactions were observed in 35 patients during the observation period. Of these, $58.6 \%$ (41/70) were grade I reactions, $15.7 \%$ (11/70) were grade II reactions, $17.1 \%$ (12/70) were grade III reactions, and $8.6 \%(6 / 70)$ were grade IV reactions. The majority $(97.1 \%$ (68/70)) of systemic reactions occurred during the maintenance phase. Risk factors included injections errors, pollen season, and increasing of dose despite previous large local reactions [145]. In contrast, Shen et al. reported that the systemic adverse reactions tend to happen during the initial treatment phase (Alutard, ALK-ABELLO, Denmark), and were mainly urticaria and angioedema [146].

\section{Side Effects of SLIT}

Shao et al. [110] enrolled 264 children aged 3-13 years old with $D e r f$-induced AR who randomly received both SLIT and pharmacotherapy or pharmacotherapy only for 12 months. Some adverse events (AEs) were found during the study period (Table 2), but no severe systemic AEs were reported [147] (Fig. 6).

\section{New Technology and Treatment Strategies}

In spite of the advances with AIT, safer and more effective AIT strategies are needed. Novel approaches to improve AIT 
Table 1 Reported systemic adverse reactions during HDM SCIT

\begin{tabular}{lcc}
\hline & China [144] & $\begin{array}{c}\text { Other East Asian } \\
\text { countries [133] }\end{array}$ \\
\hline Systemic adverse reactions & $4.8 \%(8 / 166)$ & $10.4 \%(26 / 251)$ \\
Grade 1 & $12 \%(3 / 25)$ & $81 \%(21 / 26)$ \\
Grade 2 & $60 \%(15 / 25)$ & $19 \%(5 / 26)$ \\
Grade 3 & $28 \%(7 / 25)$ & $0(0.0 \%)$ \\
Grade 4 & $0 \%(0.0 \%)$ & $0(0.0 \%)$ \\
\hline
\end{tabular}

$S C I T=$ subcutaneous immunotherapy

include use of adjuvants, recombinant allergens, DNA vaccines, and alternate routes of administration. Novel vaccine development for future immunotherapy in China can be seen in Fig. 7.

\section{Adjuvants}

A potential therapeutic method on experimental allergic asthma is to target Toll-like receptor 7 (TLR7). A synthesized versatile Toll-like receptor 7 agonist was conjugated to recombinant Der $\mathrm{f} 1$ and evaluated in a mouse model of HDM sensitization [149]. Both TLR7a-Der $\mathrm{f} 1$ and Der $\mathrm{f} 1$ treatment reduced $\operatorname{IgE}$ levels and increased $\operatorname{IgG} 1$ and $\operatorname{IgG} 2$ and with a Th2 $\rightarrow$ Th1 shift in splenocyte culture supernatant and bronchoalveolar lavage. TLR7a-Der f 1 treatment also induced a significant increase in IL-12 level, while Der f 1 only induced a slight increase in IL-12. More importantly, TLR7 agonistDer f 1 (TLR7a-Derf 1) reduced airway responsiveness and airway inflammation and protected animals from anaphylaxis upon challenge. This data indicates the significance of TLR7 in airway responsiveness in a mouse model. The protective and suppressive potential of TLR7a-Der $\mathrm{f} 1$ vaccine in dust mite allergic asthma remains to be determined in humans.

Chitosan (CS), a biodegradable material, has been reported to be a safe and effective method of allergen delivery. One study compared the efficacy between Dermatophagoides farinae (Der $f$ ) and Dermatophagoides farinae/chitosan

Table 2 Reported adverse events during SLIT

\begin{tabular}{lcc}
\hline & $\begin{array}{l}\text { China } \\
{[110]}\end{array}$ & $\begin{array}{l}\text { Other East Asian } \\
\text { countries [147] }\end{array}$ \\
\hline Exacerbation of rhinitis & $13(24.1 \%)$ & $16(18.1 \%)$ \\
Exacerbation of asthma & $8(14.8 \%)$ & - \\
Local rashes & $5(9.3 \%)$ & $4(4.5 \%)$ \\
Itching sensation in the oral cavity & $1(1.9 \%)$ & $13(14.8 \%)$ \\
$\quad$ or of the lip & $2(3.7 \%)$ & $11(12.6 \%)$ \\
Gastrointestinal disorders & $1(1.9 \%)$ & $4(4.5 \%)$ \\
Eye itching & $0(0.0 \%)$ & $0(0.0 \%)$ \\
Anaphylactic shock & & \\
\hline
\end{tabular}

SLIT $=$ sublingual immunotherapy nanoparticle vaccine (DCN) in an asthma mouse model. Compared with a control group, AHR and lung inflammation were greatly reduced in both the Der $f$ group and the DCN group. The numbers of total cells and eosinophils in BALF from these two groups also were significantly lower than those of the control group. However, mice treated with sublingual DCN showed increased higher level of IFN- $\gamma$ in the supernatant of splenocyte culture and bronchoalveolar lavage fluid and increased levels of $\operatorname{IgG} 2 \mathrm{a}$ and $\operatorname{IgA}$ in the serum compared to mice treated by $\operatorname{Der} f$ only [150].

Mesoporous silica nanoparticles (MSNs) have also gained significant attention as potential delivery vehicles and for their use as adjuvants [151]. In 2018, Peng et al. used hollow mesoporous silica nanoparticles (HMSNs) as vehicles for HDM allergen in order to improve the efficacy of SIT. Spherical HMSNs $(100 \mathrm{~nm})$ with a pore diameter of $2.897 \mathrm{~nm}$ were successfully loaded with $\operatorname{Der} f 2$ protein with a loading capacity of $90 \mu \mathrm{g} \operatorname{Der} f 2 / 1 \mathrm{mg}$ HMSNs. Its preventive effects on allergic asthma were evaluated by subcutaneous administration of Der f2-loaded HMSNs in a mouse model of Der f2induced allergic asthma. The Der f2 loaded on HMSNs released slowly in $72 \mathrm{~h}$. Their data showed that treatment with Der f2-loaded HMSNs could efficiently decrease Der f2-specific IgE levels, inflammatory cell infiltration in lung tissue, and Th2 cytokine IL4 levels in BALF. In addition, Der f2loaded HMSNs increased the Der f2-specific IgG levels, Th1 cytokine IFN- $\gamma$ levels, and induced proliferation of splenocytes to Der $f 2$ and increased IFN- $\gamma$ levels. These results showed that Der f2-loaded HMSNs were efficient in preventing allergic inflammation, and HMSNs may be potential vehicles for SIT of HDM allergy [152].

\section{Recombinant Allergens}

Lactic acid bacteria (LAB) are food-grade bacteria with "GRAS" (generally regarded as safe) status, and their antiallergic effects have already been recognized. Increasing studies have utilized the expression of various heterologous antigens in LAB as oral vaccines. Hu et al. successfully expressed the major peanut allergen Ara h 2.02 in the LAB expression system and evaluated its efficacy in an experimental animal model of peanut allergy. The goal is to develop a safe, effective, and convenient oral vaccine for peanut allergy. The results showed that systemic anaphylactic symptoms and $\mathrm{Th} 2$ responses (IgE antibody, MCP-1 level, histamine release, and IL-4 production) were significantly attenuated in the experimental groups when compared with the control group. Moreover, specific IgG2a antibody and the ratio of IFN-/IL4 were intensely increased through pretreatment with the Ara h 2.02-expressing LAB [153]. These observations suggest that this peanut allergy recombinant LAB oral vaccine, utilizing a recombinant strain which expresses a hypoallergenic peanut allergen, is a viable treatment modality in food allergy. 
Fig. 6 Mechanisms of allergenspecific immunotherapy.

Allergen-specific Treg cells generate and suppress other effector Th1 and Th2 cells, which directly or indirectly suppress mast cells and basophils, resulting in early and late desensitization of mast cells and basophils. Suppression of allergen-specific IgE and inducement of IgG4 by T cells and induction of allergen-specific IL$10^{+}$Breg cells also lead to the suppression of effector T cells [148]

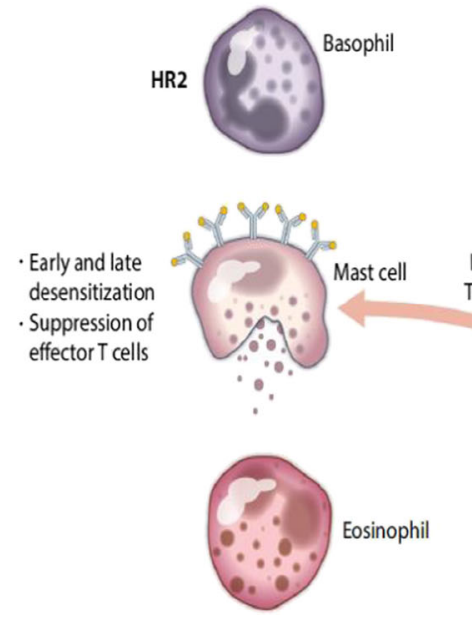

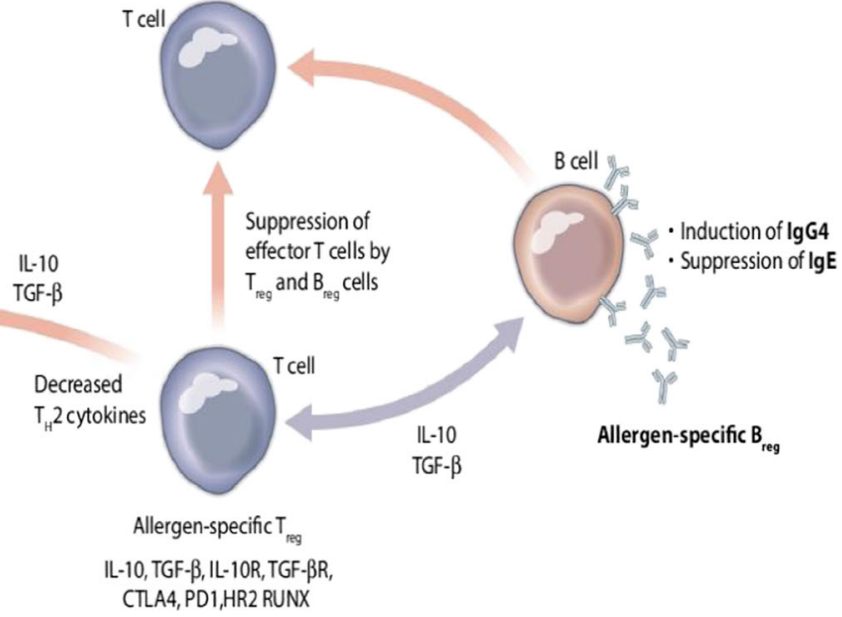

Likewise, Zhang et al. have described another LAB expression system as an oral immunotherapy agent for Der p2 [154].

\section{DNA Vaccines}

Plasmid DNA vaccines expressing allergens have been investigated as an alternative immunotherapy approach in allergy. DNA vaccines delivered by dendritic cells are more efficient than plasmid DNA vaccines. By transferring Der $p$ allergen genes into immature dendritic cells (DC), Wu et al. [155] successfully induced immune tolerance in mice with HDM asthma. The transfection of major allergens of house dust mite, Der $p 1$, and Der $p 2$ resulted in the increase of the secretion of IL-10, IL-12, and TGF-beta by DCs but did not induce the maturation of immature DCs. The Th2 responses decreased and Th1 responses increased when the asthmatic mouse $\mathrm{CD}^{+} \mathrm{T}$ cells were cocultured with transfected DCs. The transfected DCs induced the increase of regulatory $\mathrm{T}$ cells, especially the IL-10-secreting regulatory T cells in asthmatic mice in vivo, and inhibited the inflammation and Th2 responses in a regulatory-dependent manner [155]. The results provided a novel concept that DCs may be an effective target for the clinical treatment of allergic asthma at the genetic level.

\section{Rush and Cluster Immunotherapy Schedules}

Rush and cluster immunotherapy schedules accelerate immunotherapy buildup. A cluster immunotherapy schedule involves the patient receiving several allergen injections (generally two to four injections) sequentially in a single day of treatment on

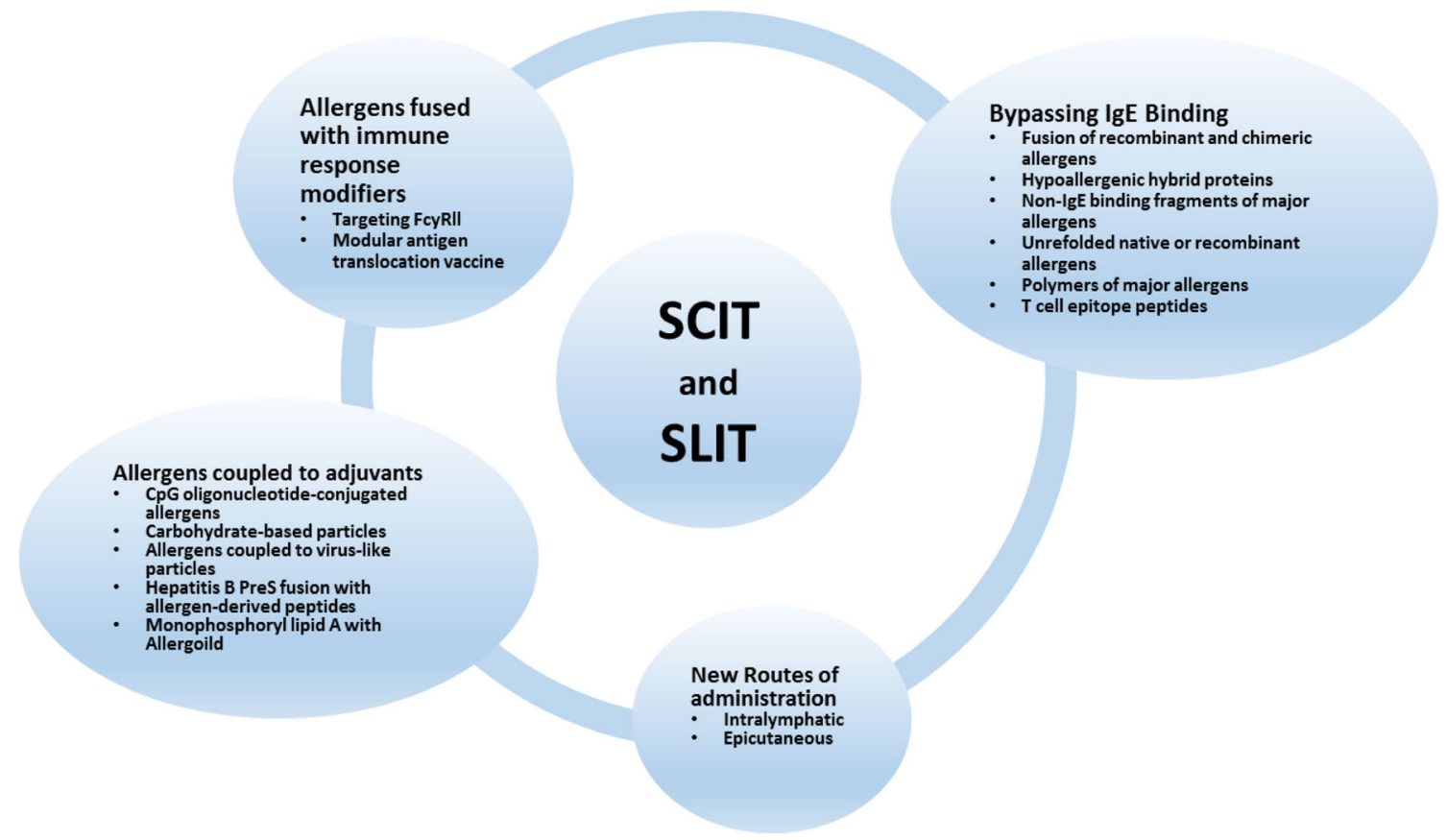

Fig. 7 Novel vaccine development for future immunotherapy 
nonconsecutive days. The maintenance dose is generally reached in 4-8 weeks. In rush immunotherapy (RIT) protocols, higher doses are administered at 15- to 60-min intervals over a 1- to 3-day period until the maintenance dose is achieved [156]. RIT shows similar and even earlier onset of clinical efficacy compared to conventional AIT, and there is no evidence to support a difference in systemic adverse reactions [157]. Similarly, the cluster schedule reduced the time to reach maintenance dose and caused mild systemic adverse reactions with no differences compared to conventional schedules [158, 159].

\section{Epicutaneous Immunotherapy}

Studies of epicutaneous immunotherapy in murine models of allergy have generated substantial data to support its safety and efficacy. In a study by Li et al. [160], mice were first given five weekly treatments of 10-1000 $\mu \mathrm{g}$ complete peanut extract (CPE) or ovalbumin (OVA) on shaved back skin and subsequently with oral CPE or OVA plus cholera toxin skin for 5 weeks and monitored for hypersensitivity responses. While CPE or OVA to structurally intact skin did not lead to allergic sensitization to peanut or OVA, cutaneous allergen application blocked the subsequent induction of the oral sensitization including inhibiting oral sensitization-induced CPE-specific IgE, IgG1, and IgG2a production in a dose-dependent fashion. Such treatment also suppressed peanut-induced anaphylaxis and modulated oral sensitization-promoted cytokine production. Cutaneous OVA application also resulted in similar results as seen with CPE application. These experimental data in animal models suggest that allergic tolerance might be achieved via the cutaneous application of allergen. However, clinical data is needed to demonstrate the efficacy and safety profile of EPIT prior to approval for routine clinical applications.

\section{Intralymphatic Immunotherapy}

Yong et al. [161] evaluated the clinical efficacy and safety of intralymphatic Der p immunotherapy for house dust mites. Patients in a control group $(n=36)$ were prescribed budesonide and salbutamol aerosol, while those in the intralymphatic immunotherapy treatment group $(n=36)$ were prescribed additional intralymphatic immunotherapy every 4 weeks. After 20 weeks, medication scores and serum Der p sIgE of patients in the immunotherapy group decreased significantly compared with the control group, with no local and systemic adverse reactions.

\section{Summary}

The five most common allergens in China are HDM, Artemisia (wormwood), Humulus japonicus (Japanese hop), Alternaria alternata, and Cladosporium herbarum, but there is regional variability. AIT for AR, asthma, and other allergic diseases in China has developed very quickly in recent years. With the support of the Chinese Medical Association (CMA) and the Chinese Medical Doctor Association (CMDA), improvements in the Chinese AIT will continue to be developed and become more widely used among allergists. The Chinese College of Allergy and Asthma (CCAA), a specialized branch of the CMDA established in 2016, will be the main certification authority for AIT.

Since 1956, conventional SCIT has been the preferred route of administration in China. SLIT has recently been gaining more widespread acceptance. So far, HDM is the only extract available commercially in China, but other commercial extracts, standardized allergens, multi-allergen mixtures, recombinant allergens, and novel approaches will hopefully become available for clinical use. This is a growing field due to the expanding potential and increasing number of allergy patients in China.

Funding Information This project was sponsored by grants from CAMS Innovation Fund for Medical Sciences (CIFMS:2016-I2M-1-003), the National Natural Science Foundation of China (81571568), and the Priority Academic Program Development of Jiangsu Higher Education Institutions (PAPD).

\section{Compliance with Ethical Standards}

Conflict of Interest The authors declare that they have no conflict of interest.

Ethical Approval This article does not contain any studies with human participants or animals performed by any of the authors.

\section{References}

1. Bousquet J, Schunemann HJ, Samolinski B, Demoly P, BaenaCagnani CE, Bachert C, Bonini S, Boulet LP, Bousquet PJ, Brozek JL, Canonica GW, Casale TB, Cruz AA, Fokkens WJ, Fonseca JA, van Wijk RG, Grouse L, Haahtela T, Khaltaev N, Kuna P, Lockey RF, Lodrup Carlsen KC, Mullol J, Naclerio R, O'Hehir RE, Ohta K, Palkonen S, Papadopoulos NG, Passalacqua G, Pawankar R, Price D, Ryan D, Simons FE, Togias A, Williams D, Yorgancioglu A, Yusuf OM, Aberer W, Adachi M, Agache I, Ait-Khaled N, Akdis CA, Andrianarisoa A, Annesi-Maesano I, Ansotegui IJ, Baiardini I, Bateman ED, Bedbrook A, Beghe B, Beji M, Bel EH, Ben Kheder A, Bennoor KS, Bergmann KC, Berrissoul F, Bieber T, Bindslev Jensen C, Blaiss MS, Boner AL, Bouchard J, Braido F, Brightling CE, Bush A, Caballero F, Calderon MA, Calvo MA, Camargos PA, Caraballo LR, Carlsen KH, Carr W, Cepeda AM, Cesario A, Chavannes NH, Chen YZ, Chiriac AM, Chivato Perez T, Chkhartishvili E, Ciprandi G, Costa DJ, Cox L, Custovic A, Dahl R, Darsow U, De Blay F, Deleanu D, Denburg JA, Devillier P, Didi T, Dokic D, Dolen WK, Douagui H, Dubakiene R, Durham SR, Dykewicz MS, El-Gamal Y, ElMeziane A, Emuzyte R, Fiocchi A, Fletcher M, Fukuda T, Gamkrelidze A, Gereda JE, Gonzalez Diaz S, Gotua M, Guzman MA, Hellings PW, Hellquist-Dahl B, Horak F, Hourihane JO, Howarth P, Humbert M, Ivancevich JC, Jackson C, Just J, Kalayci O, Kaliner MA, Kalyoncu AF, Keil T, Keith PK, Khayat G, Kim YY, Koffi N'goran B, Koppelman GH, Kowalski 
ML, Kull I, Kvedariene V, Larenas-Linnemann D, Le LT LC, Li J, Lieberman P, Lipworth B, Mahboub B, Makela MJ, Martin F, Marshall GD, Martinez FD, Masjedi MR, Maurer M, MavaleManuel S, Mazon A, Melen E, Meltzer EO, Mendez NH, Merk H, Mihaltan F, Mohammad Y, Morais-Almeida M, Muraro A, Nafti S, Namazova-Baranova L, Nekam K, Neou A, Niggemann B, Nizankowska-Mogilnicka E, Nyembue TD, Okamoto Y, Okubo K, Orru MP, Ouedraogo S, Ozdemir C, Panzner P, PaliScholl I, Park HS, Pigearias B, Pohl W, Popov TA, Postma DS, Potter P, Rabe KF, Ratomaharo J, Reitamo S, Ring J, Roberts R, Rogala B, Romano A, Roman Rodriguez M, Rosado-Pinto J, Rosenwasser L, Rottem M, Sanchez-Borges M, Scadding GK, Schmid-Grendelmeier P, Sheikh A, Sisul JC, Sole D, Sooronbaev T, Spicak V, Spranger O, Stein RT, Stoloff SW, Sunyer J, Szczeklik A, Todo-Bom A, Toskala E, Tremblay Y, Valenta R, Valero AL, Valeyre D, Valiulis A, Valovirta E, Van Cauwenberge P, Vandenplas O, van Weel C, Vichyanond $\mathrm{P}$, Viegi G, Wang DY, Wickman M, Wohrl S, Wright J, Yawn BP, Yiallouros PK, Zar HJ, Zernotti ME, Zhong N, Zidarn M, Zuberbier T, Burney PG, Johnston SL, Warner JO, World Health Organization Collaborating Center for A, Rhinitis (2012) Allergic Rhinitis and its Impact on Asthma (ARIA): Achievements in 10 years and future needs. J Allergy Clin Immunol 130:1049-1062

2. Wang XD, Zheng M, Lou HF, Wang CS, Zhang Y, Bo MY, Ge SQ, Zhang N, Zhang L, Bachert C (2016) An increased prevalence of self-reported allergic rhinitis in major Chinese cities from 2005 to 2011. Allergy 71:1170-1180

3. Guidelines for diagnosis and treatment of allergic rhinitis (2009, Wuyishan). Chin J Otorhinolaryngol Head Neck Surg 2009; 44: 977-8

4. Guideline for diagnosis and treatment of allergic rhinitis (2015, Tianjin). Chin J Otorhinolaryngol Head Neck Surg 2016; 51:6-24

5. Cheng L, Chen J, Fu Q, He S, Li H, Liu Z, Tan G, Tao Z, Wang D, Wen W, Xu R, Xu Y, Yang Q, Zhang C, Zhang G, Zhang R, Zhang Y, Zhou B, Zhu D, Chen L, Cui X, Deng Y, Guo Z, Huang Z, Huang Z, Li H, Li J, Li W, Li Y, Xi L, Lou H, Lu M, Ouyang Y, Shi W, Tao X, Tian H, Wang C, Wang M, Wang N, Wang X, Xie H, Yu S, Zhao R, Zheng M, Zhou H, Zhu L, Zhang L (2018) Chinese Society of Allergy Guidelines for diagnosis and treatment of allergic rhinitis. Allergy, Asthma Immunol Res 10:300-353

6. Alvarez-Cuesta E, Bousquet J, Canonica GW, Durham SR, Malling HJ, Valovirta E, Eaaci ITF (2006) Standards for practical allergen-specific immunotherapy. Allergy 61(Suppl 82):1-20

7. Bateman ED, Hurd SS, Barnes PJ, Bousquet J, Drazen JM, FitzGerald JM, Gibson P, Ohta K, O'Byrne P, Pedersen SE, Pizzichini E, Sullivan SD, Wenzel SE, Zar HJ (2008) Global strategy for asthma management and prevention: GINA executive summary. Eur Respir J 31:143-178

8. Ring J, Gutermuth J (2011) 100 years of hyposensitization: history of allergen-specific immunotherapy (ASIT). Allergy 66:713-724

9. Zhou H, Tao QL, Wei JM, Xu G, Cheng L (2014) Trends in specific immunotherapy for allergic rhinitis: a survey of Chinese ENT specialists. Allergy, Asthma Immunol Res 6:296-303

10. Bao Y, Chen J, Cheng L, Guo Y, Hong S, Kong W, Lai H, Li H, Li H, Li J, Li T, Lin X, Liu S, Liu Z, Lou H, Meng J, Qiu Q, Shen K, Tang W, Tao Z, Wang C, Wang X, Wei Q, Xiang L, Xie H, Xu Y, Zhang G, Zhang Y, Zheng Y, Zhi Y, Chen D, Hong H, Li Q, Liu L, Meng Y, Wang N, Wang Y, Zhou Y, Zhang L, Chinese Society of A, Chinese Allergic Rhinitis Collaborative Research G (2017) Chinese guideline on allergen immunotherapy for allergic rhinitis. J Thorac Dis 9:4607-4650

11. Expert consensus on subcutaneous immunotherapy for allergic rhinitis 2015. Chin Arch Otolaryngol Head Neck Surg 2015; 22: 379-404

12. Bousquet PJ, Burbach G, Heinzerling LM, Edenharter G, Bachert C, Bindslev-Jensen C, Bonini S, Bousquet-Rouanet L, Demoly P,
Bresciani M, Bruno A, Gjomarkaj M, Canonica GW, Darsow U, Durham S, Fokkens WJ, Giavi S, Gramiccioni C, Papadopoulos NG, Haahtela T, Kowalski ML, Magyar P, Murakozi G, Orosz M, Rohnelt C, Stingl G, Todo-Bom A, von Mutius E, Wiesner A, Wohrl S, Bousquet J, Zuberbier T (2009) GA2LEN skin test study III: minimum battery of test inhalent allergens needed in epidemiological studies in patients. Allergy 64:1656-1662

13. Bachert C, van Cauwenberge P, Olbrecht J, van Schoor J (2006) Prevalence, classification and perception of allergic and nonallergic rhinitis in Belgium. Allergy 61:693-698

14. Bauchau V, Durham SR (2004) Prevalence and rate of diagnosis of allergic rhinitis in Europe. Eur Respir J 24:758-764

15. Nathan RA, Meltzer EO, Derebery J, Campbell UB, Stang PE, Corrao MA, Allen G, Stanford R (2008) The prevalence of nasal symptoms attributed to allergies in the United States: findings from the burden of rhinitis in an America survey. Allergy Asthma Proc 29:600-608

16. Li F, Zhou Y, Li S, Jiang F, Jin X, Yan C, Tian Y, Zhang Y, Tong S, Shen X (2011) Prevalence and risk factors of childhood allergic diseases in eight metropolitan cities in China: a multicenter study. BMC Public Health 11:437

17. Zhao J, Bai J, Shen K, Xiang L, Huang S, Chen A, Huang Y, Wang J, Ye R (2010) Self-reported prevalence of childhood allergic diseases in three cities of China: a multicenter study. BMC Public Health 10:551

18. Zhang L, Han D, Huang D, Wu Y, Dong Z, Xu G, Kong W, Bachert C (2009) Prevalence of self-reported allergic rhinitis in eleven major cities in China. Int Arch Allergy Immunol 149:4757

19. Zhang Y, Zhang L (2014) Prevalence of allergic rhinitis in China. Allergy, Asthma Immunol Res 6:105-113

20. Celedon JC, Palmer LJ, Weiss ST, Wang B, Fang Z, Xu X (2001) Asthma, rhinitis, and skin test reactivity to aeroallergens in families of asthmatic subjects in Anqing, China. Am J Respir Crit Care Med 163:1108-1112

21. Wang XY, Ma TT, Wang XY, Zhuang Y, Wang XD, Ning HY, Shi HY, Yu RL, Yan D, Huang HD, Bai YF, Shan GL, Zhang B, Song QK, Zhang YF, Zhang TJ, Jia DZ, Liu XL, Kang ZX, Yan WJ, Yang BT, Bao XZ, Sun SH, Zhang FF, Yu WH, Bai CL, Wei T, Yang T, Ma TQ, Wu XB, Liu JG, Du H, Zhang L, Yan Y, Wang DY (2018) Prevalence of pollen-induced allergic rhinitis with high pollen exposure in grasslands of northern China. Allergy 73: $1232-1243$

22. Wang W, Huang X, Chen Z, Zheng R, Chen Y, Zhang G, Yang Q (2016) Prevalence and trends of sensitisation to aeroallergens in patients with allergic rhinitis in Guangzhou, China: a 10-year retrospective study. BMJ Open 6:e11085

23. Sakashita M, Hirota T, Harada M, Nakamichi R, Tsunoda T, Osawa Y, Kojima A, Okamoto M, Suzuki D, Kubo S, Imoto Y, Nakamura Y, Tamari M, Fujieda S (2010) Prevalence of allergic rhinitis and sensitization to common aeroallergens in a Japanese population. Int Arch Allergy Immunol 151:255-261

24. Osawa Y, Suzuki D, Ito Y, Narita N, Ohshima Y, Ishihara Y, Ishihara Y, Tsuchida S, Fujieda S (2012) Prevalence of inhaled antigen sensitization and nasal eosinophils in Japanese children under two years old. Int J Pediatr Otorhinolaryngol 76:189-193

25. Kato M, Yamada Y, Maruyama K, Hayashi Y (2014) Age at onset of asthma and allergen sensitization early in life. Allergol Int 63(Suppl 1):23-28

26. Yamazaki S, Shima M, Nakadate T, Ohara T, Omori T, Ono M, Sato T, Nitta H (2015) Patterns of sensitization to inhalant allergens in Japanese lower-grade schoolchildren and related factors. Int Arch Allergy Immunol 167:253-263

27. James C, Bernstein DI (2017) Allergen immunotherapy: an updated review of safety. Curr Opin Allergy Clin Immunol 17:55-59 
28. Sivam A, Tankersley M, American College of Allergy A, Immunology I, Diagnostics C (2019) Perception and practice of sublingual immunotherapy among practicing allergists in the United States: a follow-up survey. Ann Allergy Asthma Immunol

29. Bousquet J, Pfaar O, Togias A, Schunemann HJ, Ansotegui I, Papadopoulos NG, Tsiligianni I, Agache I, Anto JM, Bachert C, Bedbrook A, Bergmann KC, Bosnic-Anticevich S, Bosse I, Brozek J, Calderon M, Canonica GW, Caraballo L, Cardona V, Casale T, Cecchi L, Chu DK, Costa E, Cruz AA, Czarlewski W, Durham SR, Du Toit G, Dykewicz M, Ebisawa M, Fauquert JL, Fernandez-Rivas M, Fokkens WJ, Fonseca J, Fontaine JF, van Wijk RG, Haahtela T, Halken S, Hellings PW, Ierodiakonou D, Iinuma T, Ivancevich JC, Jacobsen L, Jutel M, Kaidashev I, Khaitov M, Kalayci O, Kleine Tebbe J, Klimek L, Kowalski ML, Kuna P, Kvedariene V, La Grutta S, Larenas-Linemann D, Lau S, Laune D, Le L, Carlsen KL, Lourenco O, Malling HJ, Marien G, Menditto E, Mercier G, Mullol J, Muraro A, O'Hehir R, Okamoto Y, Pajno GB, Park HS, Panzner P, Passalacqua G, Pham-Thi N, Roberts G, Rolland C, Rosario N, Ryan D, Samolinski B, Sanchez-Borges M, Scadding G, Shamji MH, Sheikh A, Sturm GJ, Todo Bom A, Toppila-Salmi S, ValentinRostan M, Valiulis A, Valovirta E, Ventura MT, Wahn U, Walker S, Wallace D, Waserman S, Yorgancioglu A, Zuberbier T, Group AW (2019) 2019 ARIA care pathways for allergen immunotherapy. Allergy

30. Feng M, Sun W, Cheng X (2009) Seasonal dynamics and distribution of house dust mites in China. Biosci Trends 3:210-215

31. RQ W, HY Z (2012) Two hundred thousands results of allergen specific IgE detection. Chin J Allergy Clin Immunol 6:18-23

32. Li J, Sun B, Huang Y, Lin X, Zhao D, Tan G, Wu J, Zhao H, Cao L, Zhong N, China Alliance of Research on Respiratory Allergic D (2009) A multicentre study assessing the prevalence of sensitizations in patients with asthma and/or rhinitis in China. Allergy 64:1083-1092

33. Sun JL, Shen L, Chen J, Yu JM, Yin J (2014) Mite and booklouse fauna from vacuumed dust samples from Beijing. Allergy, Asthma Immunol Res 6:257-262

34. Sun JL, Shen L, Chen J, Yu JM, Yin J (2013) Species diversity of house dust mites in Beijing, China. J Med Entomol 50:31-36

35. Zhong LH, Zhou YR, Li MZ et al (1999) Study on the breeding situations and its allergy of dust mites in Wuhan City. Chin J Public Health 15:757

36. Yu JM, Luo QH, Sun JL, Shi CL, Yin J, Zhou YL, Tang R, Zhang H, Yu Z, Chen M (2015) Diversity of house dust mite species in Xishuangbanna Dai, a tropical rainforest region in southwest China. Biomed Res Int 2015:421716

37. Li F, Chang H, Li L et al (2010) Analysis of allergen skin prick test in 1275 children. Chin J Clinicians 39:44-46

38. Huang F, Zhao Y, He J, Deng P, Zhou P, Zhou J, Zhou X, Yang Z (2010) Analyzing of the inhaled allergens profiles of allergic rhinitis patients in district of Jingmen. J Clin Otorhinolaryngol Head Neck Surg (China) 24:341-343

39. Wu QW, Cai PC, Chen ZZ, Wu XH, Kong LL, Hu L (2009) Analysis of specific allergens IgE in bronchial asthma children in Wuhan district. J Clin Hematology 22:65-67

40. Jeong KY, Lee JH, Kim EJ, Lee JS, Cho SH, Hong SJ, Park JW (2014) Current status of standardization of inhalant allergen extracts in Korea. Allergy, Asthma Immunol Res 6:196-200

41. Shi M, He WJ, Peng YP et al (2011) Detection analysis of 430 cases of patients with allergic diseases of allergen in Xiangxi minority nationality regions. China Medical Herald 8:128-130

42. Wu Y, Ai T, Luo RH et al (2011) An analysis of skin prink test in children with cough variant asthma in Chengdu areas. Sichuan Med J 32:310-312
43. Wang YX, Zhang H, Li H et al (2002) Analysis of allergen assay of 121 patients with allergic dermal diseaes. Chin J Derm Venereol 16:96-98

44. Song W, Lin X, Zhong H, Lv Z, Feng X (2011) Spectrum of sensitized inhalant allergens in allergic rhinitis patients in Liaoning Province. Chin J Allergy Clin Immunol 5:263-267

45. An LX, Zhang LH, Guan YY et al (2012) Analysis of sIgE test in 5000 patients. J Harbin Medical University 46:188-191

46. Wang X (2014) Analysis of skin prick test of inhalant allergens in allergic rhinitis. China Prac Med 9:8-10

47. Zhang CX, Wang JY, YP W. (2004) Analysis of 882 patients sIgE test with allergic skin disease in Qingdao. Chin J Dermato Venerol Integ Trad W Med 3:223-224

48. Liu CX, Gu M, Zhang H et al (2014) Detection of specific allergen in allergic children in Nantong region and its clinical significance. Journal of Clinical Medicine in Practice 18:44-47

49. Lou JT, Chen LP, Tao R et al (2006) Comparative analysis of allergens in children with asthma in and around Hangzhou district. CJCHC 14:627-629

50. Hang JG, Yao ZZ, Guan MC, et al (2011) Detection of allergen sIgE in asthma children in TaiZhou region and its clinical significance. Lab Med 26

51. Rong GS, Gao X, Liu SW et al (2008) Result analysis of the 887 cases skin prick tests. Anhui Med J 29:259-262

52. Pan XL, Gui XZ, Zhao J et al (2011) Detection and analysis of allergens in allergic patients in Wuhu region. Anhui Med J 32: $1161-1163$

53. Feng L, Geng CF, Xue W (2008) Analysis of 442 patients' sIgE test with allergic skin disease. Jiangxi Med J 43:34-36

54. Lin J (2013) Analysis on the allergens of children with allergic diseases in 350 cases. Lab Med Clin 10:435-438

55. Chen J (2012) Analysis of 552 children sIgE test. Jilin Med J 33: 3676-3677

56. Ji JZ, Chen ZG, Li M et al (2007) Analysis of common inhaled allergens in 397 asthma children in Guangzhou urban area. New Medicine 38:505-506

57. Ding HM, Chen QB, Pan WY et al (2012) Analysis of inhaled allergens in allergic rhinitis patients in Guangzhou region. Guangdong Med J 33:2157-2159

58. Liang GZ, Li FJ, Hou SB et al (2005) Analysis of allergens of allergosis in 1625 cases. Practical Clinical Medicine 6:14-16

59. Bi X, Qin Z, Lan Y (2011) Detection and analysis of allergens in 118 allergic patients. Lab Med 26:555-557

60. Wang L, Chen S, Kuang HY et al (2010) Analysis of allergens SIgE in asthma children in Hainan region. Modern Preventive Medicine 37:2834-2835

61. Dai HL, Su Y, Han JH et al (2011) 126 cases of children with allergic diseases and the specificity of total serum IgE levels of allergen detection. Chin J Lab Diagn 15:478-481

62. Wu XY, Zhang P, Pang Q et al (2014) Detection and analysis of aspiration allergens of children's bronchial asthma in Xi'an area. Progress in Modern Biomedicine 14:3849-3852

63. Yin GX (2014) Analysis of total IgE and SIgE in children with atopic dermatitis in Xining area. Qinghai Med J 44:13-14

64. Yu N, Wang JJ, Zhang XM, AX D. (2006) Analysis of 1844 patients' sIgE with allergic skin disease. Journal of Ningxia Medical College 28:396-398

65. Sun GH, Zhang JH, et al (2014) Retrospective analysis on etiology and diagnosis strategy for infants with wheezing: a report of 287 cases. Journal of Xinjiang Medical University 2014; 37:458-61

66. Wang HW, Xu PR, YN X. (2007) Analysis of allergens in children with allergic rhinitis in Xinjiang. J Clin Pediatr 25:30-32

67. Zhou Y, Wang R, HG Z. (2008) Analysis of inhaled allergens in patients with allergic rhinitis in Urumqi region. J Mod Lab Med 23:48-49 
68. Wang HW, Xiang YB, Chen X et al (2007) Analysis of allergens in patients with asthma/allergic rhinitis in Xinjiang. Journal of XINJIANG Medical University 30:1086-1088

69. Zhang L, Han DM, ZY G. (2007) A brief history of allergy. Chin J Otorhinolaryngol Head Neck Surg 14:445-448

70. Yong L, Cheng X, Li H, Li K, Li H et al (2014) Intra-lymphatic immunotherapy for adult atopic dermatitis with dust mite allergy. Immunological Journal 30:363-368

71. Yin J, Yue FM, Wang LL et al (2006) Natural course from rhinitis to asthma in the patients with autumnal pollinosis: aclinical study of 1096 patients. Chin Med J 86:1628-1632

72. Yin J, Yue FM, Wang LL et al (2005) The clinical study of the relationship between allergic rhinitis and allergic asthma in the patients with autumnal pollinosis. Chin Med J 85:1683-1687

73. Wen $\mathrm{Z}$ et al (2012) Correlation of the Artemisia and Humulus pollen count in the air and the severity of asthma symptoms in patients with autumnal pollinosis. Chinese Journal of Allergy and Clinical Immunology 6:10-17

74. Dong XQ, Liu T, Xiao JP et al (2012) Prurigo nodularis specific immune therapy research. Chinese Journal of Aesthetic Medicine 21:118-119

75. Wang M, Xing ZM, Li XL et al (2011) Effect of house-dust-mite specific immunotherapy on symptoms and quality of life in patients with perennial allergic rhinitis refractory to common methods. Chin J Otorhinolaryngol Head Neck Surg 18:634-637

76. Qu SH, Li TY, Xu G et al (2006) Evaluation of effect of special immunotherapy on allergic rhinitis and its influence of asthma. Journal of Sun Yat-sen University(Medical Sciences) 27:575-578

77. Sun LY, Guo YS et al (2011) Effect of allergen immunotherapy with standardized vaccine in patients with allergic asthma and rhinitis. Chin J Asthma 5:84-87

78. Zhou JQ, JY Z. (2007) Effect of the specific antigen immunotherapy in allergic rhinitis treatment. J Chin Pract Diagn The 21:903905

79. Song WW, Lin XP, RN C. (2014) Efficacy evaluation of standardized dust mite allergen specific immunotherapy to patients of allergic rhinitis. J Clin Otorhinolaryngol Head Neck Surg (China) 28:300-303

80. Zhang $\mathrm{J}$ (2014) Clinical efficacy and nursing intervention of alutard desensitization therapy for childhood asthma. China Pharmaceuticals 23:68-69

81. Li L et al (2013) Therapeutic efficacy of 3-year subcutaneous immunotherapy in asthmatic children allergic to mite. Chin J Contemp Pediatr 15:368-371

82. Zhou L, JH P (2013) Observations of specific immunotherapy on children allergic asthma. Anhui Medical and Pharmaceutical Journal 17:1572-1574

83. Zhao XM, Wu HQ, Lin LL et al (2013) Effect and safety analysis of Allergovit standardized mite allergen immunotherapy in patients with allergic rhinitis. J Clin Otorhinolaryngol Head Neck Surg (China) 27:1128-1131

84. Wang H, Lin X, Hao C, Zhang C, Sun B, Zheng J, Chen P, Sheng J, Wu A, Zhong N (2006) A double-blind, placebo-controlled study of house dust mite immunotherapy in Chinese asthmatic patients. Allergy 61:191-197

85. Wei JF, Liu EM, Chen KH et al (2010) Allergen sensitization changes in children with asthma often treatment with house dust mite specific immunotherapy. Journal of Chongqing Medical University 35:313-316

86. Ye HZ, Huang Y, Wang Y et al (2012) Effect of house dust mite vaccine on pulmonary function and inhaled corticosteroid doses in children with allergic asthma. J South Med Univ 32:1632-1635

87. Liu J, Zhang XB, Feng HY et al (2013) Impact factors for efficacy of specific immunotherapy in children with dust mite allergic asthma. Chin J Contemp Pediatr 15:854-859
88. Xiao SF et al (2004) Effect of immuno therapy on house dust mite allergen-specific IgG1andIgG4antibodies in nasal secretion for patients with perennial allergic rhinitis. Chin J Otorhinolaryngol 39:725-729

89. Qi S, Chen H, Huang N, Li W, Liu G, Wang Y, Hu L, Wang X, Zhang W, Zhu R (2016) Early intervention improves clinical responses to house dust mite immunotherapy in allergic rhinitis patients. Int Arch Allergy Immunol 171:234-240

90. Song Y, Long J, Wang T, Xie J, Wang M, Tan G (2018) Long-term efficacy of standardised specific subcutaneous immunotherapy in children with persistent allergic rhinitis due to multiple allergens including house dust mites. J Laryngol Otol 132:230-235

91. Xu CX, Zhang ML, Li BZ, He Y, Zou ZH, Wu QR, Tao AL, Lai H, Sun JL (2015) Efficacy of sublingual immunotherapy with Dermatophagoides farinae extract in monosensitized and polysensitized patients with allergic rhinitis: clinical observation and analysis. Biomed Res Int

92. Zhong H, Deng X, Song Z, Darsow U, Chen W, Chen S, Luo N, Hao F (2015) Immunological changes after ASIT in AD allergenspecific immunotherapy and their potential correlation with clinical response in patients with atopic dermatitis patients sensitized to house dust mite. Journal of the European Academy of Dermatology and Venereology : JEADV 29:1318-1324

93. Leng X, Ye ST (1987) One year observation of immunotherapy for Artemisia hay fever in China: a clinical and immunological study. Asian Pac J Allergy Immunol 5:167-172

94. Guan K, Wei Q, Yin J (2012) Efficacy and safety of immunotherapy with Humulus pollen extract, in Chinese. Chinese Journal of Allergy and Clinical Immunology ; 6:279-84

95. Song WW, Lin XP, Chai RN et al (2012) Long-term efficacy of allergen specific immunotherapy for pollinosis patients in northeast China. J Allergy Clin Immunol. 6

96. Wang L, Yin J, Fadel R, Montagut A, de Beaumont O et al (2014) House dust mite sublingual immunotherapy is safe and appears to be effective in moderate, persistent asthma. Allergy 69:1181-1188

97. Han H, Huang Y, Wang MK et al (2011) Influence of 2 year specific immunotherapy on skin index and pulmonary function in allergic asthma. Zhong Guo Mian Yi Xue Za Zhi 27:938-941

98. Wei H, Ou WL, Zhu CJ et al (2012) Changes of serum IgE and skin prick tests after SLIT treatment in asthma children. China Medical Herald 8:8-10

99. Xie QL, Zhen H, Hu QY et al (2010) Clinic study of the sublingual immunotherapy of Dermatophagoides farina drops in children sensitized to many kinds anaphylactogen with asthma and allergic rhinitis. Chinese Journal of New Clinical Medicine 3:1062-1065

100. Zhou LF, Wang J, Chen YQ et al (2012) Efficacy and safety of sublingual immunotherapy with house dust mite extract in poly allergen sensitized children with allergic rhinitis. J Clin Otorhinolaryngol Head Neck Surg (China) 26:913-916

101. Wang LM, Fu ZX, Lian JQ et al (2009) The clinical assessment of treating pediatric patients with allergic rhinitis and asthma by sublingual immunotherapy. Acta Acad Med Nei Mongol 31:272-275

102. Huang ZH, Liu YM, HF L. (2013) Fast onset of action of sublingual immunotherapy in dust mite caused allergic rhino conjunctivitis. J Clin Otorhinolaryngol Head Neck Surg (China) 27:579_ 58

103. Liao LC, Zhao ZL, Wu AL et al (2014) Clinical observation of specific immunotherapy in treatment of 54 patients with chronic urticaria sensitive to Dermatophagoides farinae. Chin J Derm Venereol 28:150-153

104. Yue YG, Huang HY, Huang LF et al (2014) Efficacy of specific sublingual immunotherapy with Dermatophagoides farina drops on allergic rhinitis and adenoid hypertrophy in children. J Otolaryngol Ophthal Shandong Univ 28:16-19 
105. Xie LS, Jiang YZ et al (2013) Efficacy of sublingual immunotherapy in children with perennial allergic rhinitis. Chongqing Medicine 42:3622-3625

106. Li GH, Zhu CS, Chen JQ et al (2013) Early compliance and efficacy of sublingual immunotherapy in patients with allergic rhinitis. J Clin Otorhinolaryngol Head Neck Surg (China) 27: 935-937

107. Jin X, Wang JY, Gu DS et al (2013) Clinical efficacy of sublingual immunotherapy in mite-sensitized patients with allergic rhinitis. China Journal of Modern Medicine 23:83-85

108. Wang DH, Chen L, Cheng L, Li KN, Yuan H, Lu JH, Li H (2013) Fast onset of action of sublingual immunotherapy in house dust mite-induced allergic rhinitis: a multicenter, randomized, doubleblind, placebo-controlled trial. Laryngoscope 123:1334-1340

109. Qian YQ, Fan YM, Gu HL et al (2006) Dermatophagoides farina drops in treatment of allergic asthma and atopic rhinitis. Shang Hai Yi Xue 29:841-845

110. Shao J, Cui YX, Zheng YF, Peng HF, Zheng ZL, Chen JY, Li Q, Cao LF (2014) Efficacy and safety of sublingual immunotherapy in children aged 3-13 years with allergic rhinitis. Am J Rhinol Allergy 28:131-139

111. Zhao YJ, QZ L. (2011) The observation of the efficacy and safety of cough variant asthma by Dermatophagoides Farinae drops sublingual immunotherapy. Guangdong Medicine 32:2202-2206

112. Zhu L, Zhu LP, Chen RX et al (2011) Clinical efficacy of subcutaneous and sublingual immunotherapy in mite-sensitized patients with allergic rhinitis. Chin J Otorhinolaryngol Head Neck Surg 46: 986-991

113. Zhu L, Lu J-h, Qing X et al (2010) Clinical safety and therapeutic dependence of subcutaneous and sublingual immunotherapy in mite-sensitized patients with allergic rhinitis. Chin J Otorhinolaryngol Head Neck Surg 45:444-449

114. Gui XZ, Chen Y, Zhao J et al (2010) A comparative study of the compliance between subcutaneous immunotherapy and sublingual immunotherapy in patients with allergic rhinitis. Chin Arch Otolaryngol Head Neck Surg 17:631-633

115. Cao LF, Lu Q, Gu HL et al (2007) Clinical evaluation for sublingual immunotherapy of allergic asthma and atopic rhinitis with Dermatophagoides Farinae drops. Chin J Pediat 45:736-741

116. Qin YE, Mao JR, Sang YC et al (2014) Clinical efficacy and compliance of sublingual immunotherapy with Dermatophagoides farinae drops in patients with atopic dermatitis. Int J Dermatol 53:650-655

117. Meng Q, Liu X, Li P, He L, Xie J, Gao X, Wu X, Su F, Liang Y (2016) The influence of house dust mite sublingual immunotherapy on the TSLP-OX40L signaling pathway in patients with allergic rhinitis. International Forum of Allergy \& Rhinology 6:862870

118. Wu YJ, Wang P, Liu ZX, Qiu SQ (2018) Efficacy of sublingual immunotherapy with dermatophagoides farinae drops in children with allergic rhinitis and the change of TGF-beta and IL-13 mRNA level. J Clin Otorhinolaryngol Head Neck Surg (China) 32:256-259

119. Zhong C, Yang W, Li Y, Zou L, Deng Z, Liu M, Huang X (2018) Clinical evaluation for sublingual immunotherapy with Dermatophagoides farinae drops in adult patients with allergic asthma. Ir J Med Sci 187:441-446

120. Guo Y, Li Y, Wang D, Liu Q, Liu Z, Hu L (2017) A randomized, double-blind, placebo controlled trial of sublingual immunotherapy with house-dust mite extract for allergic rhinitis. Am J Rhinol Allergy 31:42-47

121. Feng B, Xiang H, Jin H, Gao J, Huang S, Shi Y, Chen R, Chen B (2017) Efficacy of sublingual immunotherapy for house dust miteinduced allergic rhinitis: a meta-analysis of randomized controlled trials. Allergy, Asthma Immunol Res 9:220-228
122. Chen Z, Qian Y, Liu S, Huang L, Xu S, Yin W, Chen Y, Wu H, Wang G (2015) Onset time and efficacy of sublingual immunotherapy with Dermatophagoides farinae drops in children with allergic rhinitis. Chin J Otorhinolaryngol Head Neck Surg 50: 622-626

123. Lin X, Lin H, Wei X, Huang Q (2017) The efficacy and safety of sublingual immunotherapy in children and adult patients with allergic rhinitis. Allergol Immunopathol 45:457-462

124. Lin Z, Liu Q, Li T, Chen D, Chen D, Xu R (2016) The effects of house dust mite sublingual immunotherapy in patients with allergic rhinitis according to duration. International Forum of Allergy \& Rhinology 6:82-87

125. Canonica GW, Cox L, Pawankar R, Baena-Cagnani CE, Blaiss M, Bonini S, Bousquet J, Calderon M, Compalati E, Durham SR, van Wijk RG, Larenas-Linnemann D, Nelson H, Passalacqua G, Pfaar O, Rosario N, Ryan D, Rosenwasser L, Schmid-Grendelmeier P, Senna G, Valovirta E, Van Bever H, Vichyanond P, Wahn U, Yusuf O (2014) Sublingual immunotherapy: World Allergy Organization position paper 2013 update. World Allergy Organ J 7:6

126. Dantzer JA, Wood RA (2019) Next-generation approaches for the treatment of food allergy. Curr Allergy Asthma Rep 19:5

127. Lanser BJ, Leung DYM (2018) The current state of epicutaneous immunotherapy for food allergy: a comprehensive review. Clin Rev Allergy Immunol 55:153-161

128. Scurlock AM (2018) Oral and sublingual immunotherapy for treatment of IgE-mediated food allergy. Clin Rev Allergy Immunol 55:139-152

129. Wai CYY, Leung NYH, Leung PSC, Chu KH (2017) Immunotherapy of food allergy: a comprehensive review. Clin Rev Allergy Immunol

130. O'Mahony L, Akdis M, Crameri R, Akdis CA (2010) Novel immunotherapeutic approaches for allergy and asthma. Autoimmunity 43:493-503

131. Wang ZX, Shi H (2017) Single-allergen sublingual immunotherapy versus multi-allergen subcutaneous immunotherapy for children with allergic rhinitis. Journal of Huazhong University of Science and Technology Medical sciences $=$ Hua zhong ke ji da xue xue bao Yi xue Ying De wen ban = Huazhong keji daxue xuebao Yixue Yingdewen ban 37:407-411

132. Luo X, Hong H, Tang J, Wu X, Lin Z, Ma R, Fan Y, Xu G, Liu D, $\mathrm{Li} \mathrm{H}$ (2016) Increased expression of miR-146a in children with allergic rhinitis after allergen-specific immunotherapy. Allergy, Asthma Immunol Res 8:132-140

133. Nahm DH, Kim ME, Kwon B, Cho SM, Ahn A (2016) Clinical efficacy of subcutaneous allergen immunotherapy in patients with atopic dermatitis. Yonsei Med J 57:1420-1426

134. Okamoto Y, Fujieda S, Okano M, Yoshida Y, Kakudo S, Masuyama K (2017) House dust mite sublingual tablet is effective and safe in patients with allergic rhinitis. Allergy 72:435-443

135. Eifan AO, Akkoc T, Yildiz A, Keles S, Ozdemir C, Bahceciler NN, Barlan IB (2010) Clinical efficacy and immunological mechanisms of sublingual and subcutaneous immunotherapy in asthmatic/rhinitis children sensitized to house dust mite: an open randomized controlled trial. Clin Exp Allergy 40:922-932

136. Fujimura T, Kawamoto S (2015) Spectrum of allergens for Japanese cedar pollinosis and impact of component-resolved diagnosis on allergen-specific immunotherapy. Allergol Int 64:312320

137. Sakaguchi M, Hirahara K, Fujimura T, Toda M (2011) Approaches to immunotherapies for Japanese cedar pollinosis. Auris Nasus Larynx 38:431-438

138. Fujimura T, Okamoto $Y$ (2010) Antigen-specific immunotherapy against allergic rhinitis: the state of the art. Allergol Int 59:21-31

139. Okubo K, Gotoh M, Fujieda S, Okano M, Yoshida H, Morikawa H, Masuyama K, Okamoto Y, Kobayashi M (2008) A randomized 
double-blind comparative study of sublingual immunotherapy for cedar pollinosis. Allergol Int 57:265-275

140. Yang Y, Zhou W, Chen A (2016) Efficacy of sublingual immunotherapy for cedar pollinosis: a systematic review and meta-analysis. Ann Allergy Asthma Immunol 117:348-353

141. Okamoto Y, Okubo K, Yonekura S, Hashiguchi K, Goto M, Otsuka T, Murata T, Nakao Y, Kanazawa C, Nagakura H, Okawa T, Nakano K, Hisamitsu M, Kaneko S, Konno A (2015) Efficacy and safety of sublingual immunotherapy for two seasons in patients with Japanese cedar pollinosis. Int Arch Allergy Immunol 166:177-188

142. Gotoh M, Kaminuma O, Hiroi T, Okubo K (2018) Microarraybased multivariate analysis of the effectiveness of sublingual immunotherapy for cedar pollinosis. Allergy, Asthma Immunol Res 10:562-569

143. (1993) Position paper: Immunotherapy with hymenoptera venoms. (EAACI) The European Academy of Allergology and Clinical Immunology. Allergy 48:36-46

144. Lan G, Xue D, Wang M et al (2009) Analysis of adverse effects of allergen test and allergen-specific immunotherapy. Chin J Asthma $3: 22-25$

145. Wen L, Wen Z, Yang N (2014) Risk factors and management of systemic reactions induced by subcutaneous immunotherapy. Nat'l Med J China 94:3001-3004

146. Shen Y, Hong SL, Zhang M, Ke X (2017) Observation of systemic adverse reactions by specific immunotherapy and analysis of risk factors in allergic rhinitis. Chin J Otorhinolaryngol Head Neck Surg 52:801-805

147. Park IH, Hong SM, Lee HM (2012) Efficacy and safety of sublingual immunotherapy in Asian children. Int J Pediatr Otorhinolaryngol 76:1761-1766

148. Akdis CA, Akdis M (2015) Advances in allergen immunotherapy: aiming for complete tolerance to allergens. Sci Transl Med 7: 280ps6

149. Ma L, Xiao X, Ma Y, Wu H, Qiu S, Li J, Yang P, Liu Z (2017) Effect of activation of Toll-like receptor 7 in the inhibition of allergic asthma on a mouse model. Am J Transl Res 9:2143-2152

150. Yu H, Liu Z, Guo H, Zhou Y (2011) Therapeutic effect on murine asthma with sublingual use of Dermatophagoides farinae/chitosan nanoparticle vaccine. Chin J Parasitol Parasit Dis 29:4-9
151. Mody KT, Popat A, Mahony D, Cavallaro AS, Yu CZ, Mitter N (2013) Mesoporous silica nanoparticles as antigen carriers and adjuvants for vaccine delivery. Nanoscale 5:5167-5179

152. Peng X, Liang Y, Yin Y, Liao H, Li L (2018) Development of a hollow mesoporous silica nanoparticles vaccine to protect against house dust mite induced allergic inflammation. Int J Pharm 549: 115-123

153. Hu MS, Chen W, et al (2013) Preparation and evaluation of peanut allergy recombinant lactic acid bacteria oral vaccine. Jiang Nan Da Xue Xue Wei Lun Wen

154. Zhang Q, Ai C (2016) Development of house dust mite vaccine. Methods in Molecular Biology (Clifton, NJ) 1403:739-751

155. Wu K, CZ W (2005) Study of the induction of immune tolerance by dendritic cells transfected with allergens genes in a mouse model of asthma. Di San Jun Yi Da Xue Xue Wei Lun Wen

156. Calabria CW (2013) Accelerated immunotherapy schedules. Curr Allergy Asthma Rep 13:389-398

157. Qiu Q, Xu M, Lu C, Chen J, Chen S, Kong W, Han H (2016) Safety and efficacy of rush allergen-specific immunotherapy in Chinese allergic rhinitis patients. Int J Immunopathol Pharmacol 29:720-725

158. Zhang L, Wang C, Han D, Wang X, Zhao Y, Liu J (2009) Comparative study of cluster and conventional immunotherapy schedules with dermatophagoides pteronyssinus in the treatment of persistent allergic rhinitis. Int Arch Allergy Immunol 148:161169

159. Fan QJ, Liu GJ, Liu XJ, Peng C (2013) Comparative study on cluster and conventional immunotherapy in patients with allergic rhinitis. Yi Xue Yan Jiu Za Zhi 42:123-127

160. Li W, Zhang Z, Saxon A, Zhang K (2012) Prevention of oral peanut allergy sensitization via skin application of peanut allergen in a murine model. Allergy 67:622-629

161. Yong L, Gao CF, Cheng XD et al (2013) Clinical efficacy of intralymphatic immunotherapy for allergic asthma. Chin J Allergy Clin Immunol 7:160-166

Publisher's Note Springer Nature remains neutral with regard to jurisdictional claims in published maps and institutional affiliations. 